Article

\title{
Modeling Cyclic Fatigue Hysteresis Loops of 2D Woven Ceramic Matrix Composites at Elevated Temperatures in Steam
}

\author{
Longbiao Li
}

College of Civil Aviation, Nanjing University of Aeronautics and Astronautics, No. 29, Yudao St., Nanjing 210016, China; 1lb451@nuaa.edu.cn; Tel./Fax: +86-25-8489-5963

Academic Editor: Luciano Feo

Received: 20 March 2016; Accepted: 18 May 2016; Published: 27 May 2016

\begin{abstract}
In this paper, the cyclic fatigue hysteresis loops of $2 \mathrm{D}$ woven $\mathrm{SiC} / \mathrm{SiC}$ ceramic matrix composites (CMCs) at elevated temperatures in steam have been investigated. The interface slip between fibers and the matrix existing in matrix cracking modes 3 and 5, in which matrix cracking and interface debonding occurred in longitudinal yarns, is considered as the major reason for hysteresis loops of 2D woven CMCs. The hysteresis loops of 2D SiC/SiC composites corresponding to different peak stresses, test conditions, and loading frequencies have been predicted using the present analysis. The damage parameter, i.e., the proportion of matrix cracking mode 3 in the entire matrix cracking modes of the composite, and the hysteresis dissipated energy increase with increasing fatigue peak stress. With increasing cycle number, the interface shear stress in the longitudinal yarns decreases, leading to transition of interface slip types of matrix cracking modes 3 and 5.
\end{abstract}

Keywords: ceramic matrix composites (CMCs); woven; hysteresis loops; matrix cracking; interface debonding

\section{Introduction}

With the demand for high thrust-weight ratio and more efficient aero-engines, the temperature of the turbine sections will be raised to a level exceeding the limit of current metallic materials. New materials will have to be tested and validated at very high temperatures that surpass $1300{ }^{\circ} \mathrm{C}$. Ceramic matrix composites (CMCs) are lighter than superalloys and maintain structural integrity even at higher temperatures, desirable qualities for improving-aero engine efficiency, and have already been implemented in some aero-engines' components [1]. The CMC combustion chamber and high-pressure turbine components were designed and tested in the ground testing of GEnx aero engine [2]. The CMC rotating low-pressure turbine blades in a F414 turbofan demonstrator engine were successfully tested for 500 grueling cycles to validate the unprecedented temperature and durability capabilities by GE Aviation. The CMC tail nozzles were designed and fabricated by Snecma (SAFRAN) and completed the first commercial flight on CFM56-5B aero engine on 2015. CMCs will play a key role in the performance of CFM's LEAP turbofan engine, which will enter into service in 2016 for Airbus A320 and 2017 for Boeing 737 max. In these applications, the CMCs will be subjected to varying temperatures, pressures, and degrading environments like water vapor. Such environments can cause rapid oxidation, which is a primary mechanism of environmental degradation of CMCs.

Under cyclic loading, the shape, location, and area of hysteresis loops can reveal the internal damage evolution of CMCs [3,4]. Kotil et al. [5] investigated the effect of interface shear stress on the shape and area of hysteresis loops of unidirectional CMCs. Pryce and Smith [6] investigated the effect of interface partially debonding on hysteresis loops of unidirectional CMCs by assuming purely frictional load transfer between fibers and the matrix. Ahn and Curtin [7] investigated the 
effect of matrix stochastic cracking on hysteresis loops of unidirectional CMCs and compared it with the Pryce-Smith model [6]. Solti et al. [8] investigated the effect of the interface partially and completely debonding on hysteresis loops of unidirectional CMCs using the maximum interface shear strength criterion to determine the interface slip lengths. Vagaggini et al. [9] investigated the effect of interface debonded energy on hysteresis loops of unidirectional CMCs based on the Hutchinson-Jensen fiber pull-out model [10]. Cho et al. [11] investigated the evolution of interface shear stress under cyclic-fatigue loading from frictional heating measurements. Li et al. investigated the effect of interface debonding [12], fiber Poisson contraction [13], fiber fracture [14] and interface wear [15] on hysteresis loops of unidirectional CMCs, and developed an approach to estimate interface shear stress in unidirectional CMCs through hysteresis loops' area [16]. The shape, location, and area of the hysteresis loops can be used to reveal the internal damage and thermal residual stresses (TRS) developed during mechanical loading and fabrication of CMCs [17]. Steen [18] and Camus et al. [19] found that the axial TRS at a given temperature and for a given composite specimen can be determined from the coordinates of that common intersection point (CIP) by extrapolation of the compliance slopes of the top linear portion at each reloading-unloading hysteresis loop. Mei [20] obtained the thermal stress stresses in two $\mathrm{SiC}$ ceramic matrix composite system reinforced with carbon fiber $(\mathrm{C} / \mathrm{SiC})$ and silicon carbide fiber $(\mathrm{SiC} / \mathrm{SiC})$ by solving the geometric intersection points of the regression lines of consecutive unloading/reloading hysteresis loops. It was found that the C/SiC composite yielded a great TRS, leading to microcracks opening once it was cooled down from the processing temperature to room temperature; however, the $\mathrm{SiC} / \mathrm{SiC}$ composite apparently yielded a negligible TRS (close to zero) due to the SiC fibers having nearly the same coefficient of thermal expansion (CTE) as the $\mathrm{SiC}$ matrix, meaning the thermal misfit stress was equal to zero. Mei and Cheng [21] measured the TRS of needled, 2D, 2.5D, and 3D C/SiC composites through solving the $Y$-coordinates of the CIP of the regression lines of the reloading-unloading hysteresis loops. It was found that highly ordered fiber arrangements oriented in the same direction are more advantageous in releasing thermal misfit stress in the absence of transverse fiber constraint by producing more transverse cracks and thus leaving less TRS in the composite. Dassios et al. [22] measured the TRS of an un-notched and notched cross-ply $\mathrm{SiC}$ / Barium Magnesium Alumina Silicate (SiC/BMAS) composite at room temperature through solving the CIP of the regression lines of the reloading-unloading hysteresis loops. It was found that the tensile curve of double-edge notched specimens did not exhibit a CIP, which may be relieved in notched specimens due to stress concentration gradients acting in the neighborhood of the notch root, which cancels out the negative TRS state of the matrix. Dassios and Matikas [23] examined the efficiency of two TRS-prediction models using the coordinates of experimental CIPs, self-assembled in the tensile domains of cyclically-loaded SiC/BMAS composite. Kuo and Chou [24] investigated matrix cracking in cross-ply CMCs and classified the multiple cracking states into five modes, in which cracking modes 3 and 5 involve matrix cracking and interface debonding in the $0^{\circ}$ plies. Lamon [25] distinguished the matrix multicracking of 2D woven CMCs into three main steps, and illustrated the schematic diagram showing the evolution of matrix multicracking. It was found that matrix cracking modes 3 and 5 also existed in 2D woven CMCs. For CMCs being used within combustion chambers, one of the main byproducts of the combustion process is water vapor. The presence of steam within the environment significantly increases the degradation of non-oxide CMCs, i.e., the degradation of interface shear stress under cyclic fatigue loading. The damage extent and damage evolution process can be monitored through fatigue hysteresis loops. However, the fatigue hysteresis loops of CMCs at elevated temperature in steam conditions have not been investigated.

The objective of this paper is to investigate the fatigue hysteresis loops of 2D woven $\mathrm{SiC} / \mathrm{SiC}$ composite at elevated temperatures in steam. The fatigue hysteresis loops can be used to reveal internal damage evolution of CMCs. The interface slip between fibers and the matrix existent in matrix cracking modes 3 mode 5 , in which matrix cracking and interface debonding occurred in the longitudinal yarns, is considered as the major reason for the fatigue hysteresis loops of $2 \mathrm{D}$ woven 
CMCs. The fatigue hysteresis loops of a 2D woven $\mathrm{SiC} / \mathrm{SiC}$ composite, corresponding to different peak stresses, test conditions, and loading frequencies, have been predicted using the present analysis.

\section{Materials and Experimental Procedures}

\section{1. $2 \mathrm{D}$ Woven $\mathrm{SiC} / \mathrm{SiC}$ Composite at $1000^{\circ} \mathrm{C}$ in Steam}

The Ceramic Grade (CG) NICALON ${ }^{\mathrm{TM}}$ (Nippon Carbon Company, Ltd., Tokyo, Japan) fiber-reinforced silicon carbide matrix composites ( $\mathrm{SiC} / \mathrm{SiC} \mathrm{CMCs}$ ) were provided by Materials and Electrochemical Research (MER) Corporation (Tucson, AZ, USA) [26]. The material was manufactured using a new Chemical Vapor Infiltration (CVI)/Polymer Infiltration Pyrolysis (PIP) method, to achieve less than $5 \%$ porosity. The eight harness satin weave (8HSW) CG NICALON ${ }^{\mathrm{TM}}$ plies were coated in Boron Nitride (BN) and then $\mathrm{SiC}$, using CVI techniques to achieve optimum CMC properties. The fiber volume fraction was $21.5 \%$ and the average density was $2.1 \mathrm{~g} / \mathrm{cm}^{3}$. The dog-bone shaped specimens were cut from composite panels using diamond grinding.

The tension-tension fatigue experiments at $1000^{\circ} \mathrm{C}$ in steam condition were conducted on an MTS 810 Material Test System $5000 \mathrm{lb}$ capacity servo-hydraulic machine (MTS System Crop., Minneapolis, MN, USA). An MTS high temperature extensometer, MTS Model 632.53 E-14, with six-inch aluminum legs, was used to measure strain throughout the test. Both the top and bottom sets of wedges were cooled with $15^{\circ} \mathrm{C}$ water by a Neslab Coolflow Refrigerated Recirculator (MTS System Crop., Minneapolis, MN, USA), to ensure the grips would stay at acceptable temperature levels and the furnace at elevated temperatures. The steam was generated with an Amteco Chromalox 2110 Steam Generator and distilled water (AMTECO Inc., West Chester, PA, USA). The fatigue experiments were performed under load control at a sinusoidal loading frequency of $1 \mathrm{~Hz}$. The fatigue load ratio (minimum to maximum stress) was 0.1 , and the maximum number of applied cycles was defined to be 200,000 cycles.

\section{2. $2 \mathrm{D}$ Woven $\mathrm{SiC} / \mathrm{SiC}$ Composite at $1200^{\circ} \mathrm{C}$ in Steam}

Hi-Nicalon ${ }^{\mathrm{TM}}$ (Nippon Carbon Co., Ltd., Tokyo, Japan) fiber-reinforced silicon carbide matrix composites were manufactured by Hyper-Therm High Temperature Composites, Inc. (Huntington Beach, CA, USA) [27]. The material was manufactured using CVI of Hyper SiC oxidation inhibited matrix material into the woven Hi-Nicalon fiber preforms. The composite consisted of eight plies of Hi-Nicalon $\left[0^{\circ} / 90^{\circ}\right]$ fabric woven in $8 \mathrm{HSW}$. Prior to matrix densification, the preforms were coated with pyrolytic carbon to decrease interface bonding between fibers and the matrix, in order to increase the strength and toughness of the composite. The fiber volume fraction was $34.8 \%$ and the density of the composite was $2.56 \mathrm{~g} / \mathrm{cm}^{3}$. The dog-bone shaped specimens were cut from composite panels using diamond grinding.

The tension-tension fatigue experiments at $1200^{\circ} \mathrm{C}$ in steam condition were conducted on an MTS 810 Material Test System $5000 \mathrm{lb}$ capacity servo-hydraulic machine (MTS System Crop., Minneapolis, MN, USA), equipped with hydraulic water-cooled collet grips, a compact two-zone resistance-heater furnace, and two temperature controllers. The wedge grips were cooled using $15^{\circ} \mathrm{C}$ water from the Naslab model HX-75 chiller. The steam was generated by an AMTECO steam Generator (AMTECO Inc., West Chester, PA, USA) to create a near $100 \%$ steam environment. A high temperature extensometer, MTS Model 632.53 E-14, was used to measure the strain throughout the test. The tension-tension fatigue tests were performed under load control at a sinusoidal loading frequency of 0.1 and $1 \mathrm{~Hz}$. The fatigue load ratio (minimum to maximum stress) was 0.05 , and the maximum number of applied cycles was determined to be 200,000 cycles.

\section{Hysteresis Loops Models of 2D Woven CMCs}

Under cyclic fatigue loading, the matrix cracking modes in 2D woven CMCs can be divided into five different types, i.e., mode 1: transverse cracking in transverse yarns; mode 2: transverse cracking 
and matrix cracking occurred in transverse and longitudinal yarns with perfect fiber/matrix interface bonding in longitudinal yarns; mode 3: transverse cracking and matrix cracking occurred in transverse and longitudinal yarns with interface debonding in longitudinal yarns; mode 4: matrix cracking in longitudinal yarns with interface bonding; and mode 5: matrix cracking in longitudinal yarns with interface debonding, as shown in Figure 1. Upon unloading and subsequent reloading, the frictional slip occurring between fibers and the matrix in the longitudinal yarns is the major reason for the hysteresis loops of 2D woven CMCs. The hysteresis loops can be divided into four different cases, i.e., Case 1: fiber slips completely relative to matrix when interface partially debonds; Case 2: fiber slips partially relative to matrix when interface partially debonds; Case 3: fiber slips partially relative to matrix when interface completely debonds; and Case 4: fiber slips completely relative to matrix when interface completely debonds.

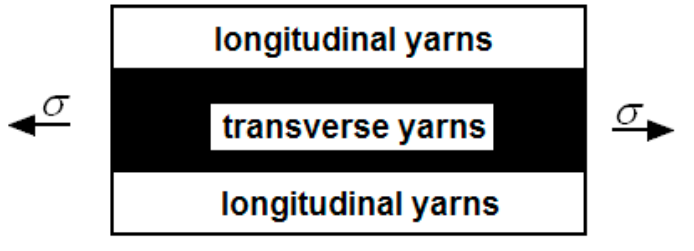

(a)

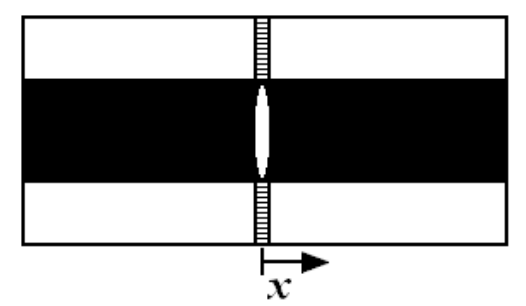

(c)

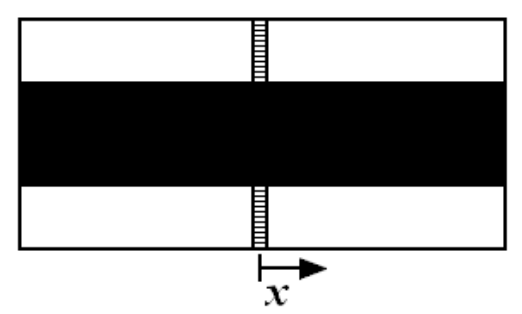

(e)

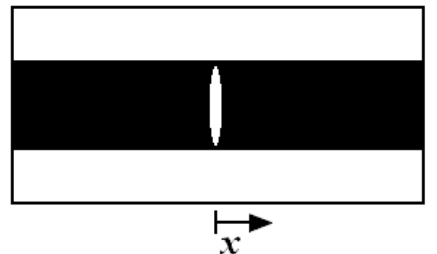

(b)

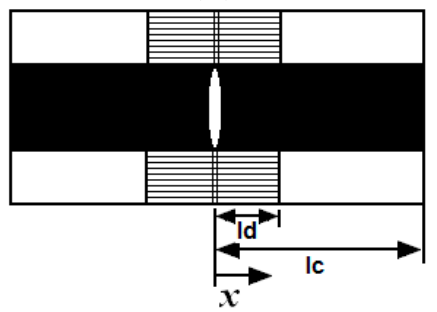

(d)

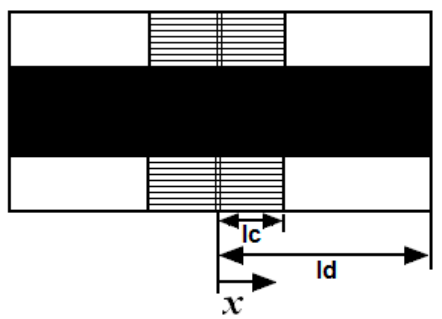

(f)

Figure 1. The undamaged state and five damaged modes of 2D woven CMCs: (a) undamaged composite; (b) mode 1: transverse cracking; (c) mode 2: transverse cracking and matrix cracking with perfect fiber/matrix bonding; (d) mode 3: transverse cracking and matrix cracking with fiber/matrix interface debonding; (e) mode 4: matrix cracking with perfect fiber/matrix bonding; and (f) mode 5: matrix cracking with fiber/matrix debonding.

\subsection{Matrix Cracking Mode 3}

For matrix cracking mode 3 , the fiber axial stress distribution upon unloading when interface partially debonding is determined by Equation (1):

$$
\left\{\begin{array}{l}
\sigma_{\mathrm{f}}(x)=\frac{1}{V_{\mathrm{f}_{\mathrm{f}} \text { axial }}} \sigma+\frac{2 \tau_{\mathrm{i}}}{r_{\mathrm{f}}} x, x \in(0, y) \\
\sigma_{\mathrm{f}}(x)=\frac{1}{V_{\mathrm{f}_{\mathrm{f}} \text { axial }}} \sigma+\frac{2 \tau_{\mathrm{i}}}{r_{\mathrm{f}}}(2 y-x), x \in\left(y, l_{\mathrm{d}}\right) \\
\sigma_{\mathrm{f}}(x)=\sigma_{\mathrm{fo}}+\left[\frac{1}{V_{\mathrm{f} \_ \text {axial }}} \sigma+\frac{2 \tau_{\mathrm{i}}}{r_{\mathrm{f}}}\left(2 y-l_{\mathrm{d}}\right)-\sigma_{\mathrm{fo}}\right] \exp \left(-\rho \frac{x-l_{\mathrm{d}}}{r_{\mathrm{f}}}\right), x \in\left(l_{\mathrm{d}}, l_{\mathrm{c}} / 2\right)
\end{array}\right.
$$


where $V_{\mathrm{f} \_ \text {axial }}$ denotes the fiber volume content in the longitudinal direction; $r_{\mathrm{f}}$ denotes the fiber radius; $\tau_{\mathrm{i}}$ denotes the fiber/matrix interface shear stress in longitudinal yarns; $l_{\mathrm{c}}$ denotes the matrix crack spacing; $l_{\mathrm{d}}$ denotes the interface debonded length; $y$ denotes the unloading interface counter-slip length; $\sigma_{\mathrm{fo}}$ denotes the fiber axial stress in the interface bonded region; and $\rho$ denotes the shear-lag model parameter.

Upon reloading, the fiber axial stress distribution when the interface partially debonds is determined by Equation (2):

$$
\left\{\begin{array}{l}
\sigma_{\mathrm{f}}(x)=\frac{1}{V_{\mathrm{f} a x i a l}} \sigma-\frac{2 \tau_{\mathrm{i}}}{r_{\mathrm{f}}} x, x \in(0, z) \\
\sigma_{\mathrm{f}}(x)=\frac{1}{V_{\mathrm{f} \_ \text {axial }}} \sigma+\frac{2 \tau_{\mathrm{i}}}{r_{\mathrm{f}}}(x-2 z), x \in(z, y) \\
\sigma_{\mathrm{f}}(x)=\frac{1}{V_{\mathrm{f} \_ \text {axial }}} \sigma-\frac{2 \tau_{\mathrm{i}}}{r_{\mathrm{f}}}(x-2 y+2 z), x \in\left(y, l_{\mathrm{d}}\right) \\
\sigma_{\mathrm{f}}(x)=\sigma_{\mathrm{fo}}+\left[\frac{1}{V_{\mathrm{f} \_ \text {axial }}} \sigma-\frac{2 \tau_{\mathrm{i}}}{r_{\mathrm{f}}}\left(l_{\mathrm{d}}-2 y+2 z\right)-\sigma_{\mathrm{fo}}\right] \exp \left(-\rho \frac{x-l_{\mathrm{d}}}{r_{\mathrm{f}}}\right), x \in\left(l_{\mathrm{d}}, l_{c} / 2\right)
\end{array}\right.
$$

where $z$ denotes the reloading interface new slip length.

When damage forms within the composite, the composite strain is determined from Equation (3), which assumes that the composite strain is equivalent to the average strain in an undamaged fiber:

$$
\varepsilon_{\mathrm{c}}=\frac{2}{E_{\mathrm{f}} l_{c}} \int_{l_{c} / 2} \sigma_{\mathrm{f}}(x) d x-\left(\alpha_{\mathrm{c}}-\alpha_{\mathrm{f}}\right) \Delta \mathrm{T}
$$

where $E_{\mathrm{f}}$ denotes the fiber elastic modulus; $\alpha_{\mathrm{f}}$ and $\alpha_{\mathrm{c}}$ denote the fiber and composite thermal expansion coefficient, respectively; and $\Delta \mathrm{T}$ denotes the temperature difference between fabricated temperature $\mathrm{T}_{0}$ and test temperature $\mathrm{T}_{1}\left(\Delta \mathrm{T}=\mathrm{T}_{1}-\mathrm{T}_{0}\right)$.

Substituting Equations (1) and (2) into Equation (3), the unloading and reloading strains when the interface partially debonds are determined by Equations (4) and (5):

$$
\begin{gathered}
\varepsilon_{\mathrm{cu}}=\frac{\sigma}{V_{\mathrm{f}_{-} \text {axial }} E_{\mathrm{f}}}+4 \frac{\tau_{\mathrm{i}}}{E_{\mathrm{f}}} \frac{y^{2}}{r_{\mathrm{f}} l_{\mathrm{c}}}-2 \frac{\tau_{\mathrm{i}}}{E_{\mathrm{f}}} \frac{\left(2 y-l_{\mathrm{d}}\right)\left(2 y-l_{\mathrm{c}}+l_{\mathrm{d}}\right)}{r_{\mathrm{f}} l_{\mathrm{c}}}-\left(\alpha_{\mathrm{c}}-\alpha_{\mathrm{f}}\right) \Delta \mathrm{T} \\
\varepsilon_{\mathrm{cr}}=\frac{\sigma}{V_{\mathrm{f}_{\mathrm{a}} \text { axial }} E_{\mathrm{f}}}-4 \frac{\tau_{\mathrm{i}}}{E_{\mathrm{f}}} \frac{z^{2}}{r_{\mathrm{f}} l_{\mathrm{c}}}+\frac{4 \tau_{\mathrm{i}}}{E_{\mathrm{f}}} \frac{(y-2 z)^{2}}{r_{\mathrm{f}} l_{\mathrm{c}}}+2 \frac{\tau_{\mathrm{i}}}{E_{\mathrm{f}}} \frac{\left(l_{\mathrm{d}}-2 y+2 z\right)\left(l_{\mathrm{d}}+2 y-2 z-l_{\mathrm{c}}\right)}{r_{\mathrm{f}} l_{\mathrm{c}}}-\left(\alpha_{\mathrm{c}}-\alpha_{\mathrm{f}}\right) \Delta \mathrm{T}
\end{gathered}
$$

when the interface completely debonds, the unloading and reloading strains are determined by Equations (6) and (7):

$$
\begin{gathered}
\varepsilon_{\mathrm{cu}}=\frac{\sigma}{V_{\mathrm{f} \_ \text {axial }} E_{\mathrm{f}}}+4 \frac{\tau_{\mathrm{i}}}{E_{\mathrm{f}}} \frac{y^{2}}{r_{\mathrm{f}} l_{\mathrm{c}}}-2 \frac{\tau_{\mathrm{i}}}{E_{\mathrm{f}}} \frac{\left(2 y-l_{\mathrm{c}} / 2\right)^{2}}{r_{\mathrm{f}} l_{\mathrm{c}}}-\left(\alpha_{\mathrm{c}}-\alpha_{\mathrm{f}}\right) \Delta \mathrm{T} \\
\varepsilon_{\mathrm{cr}}=\frac{\sigma}{V_{\mathrm{f} \_ \text {axial }} E_{\mathrm{f}}}-4 \frac{\tau_{\mathrm{i}}}{E_{\mathrm{f}}} \frac{z^{2}}{r_{\mathrm{f}} l_{\mathrm{c}}}+4 \frac{\tau_{\mathrm{i}}}{E_{\mathrm{f}}} \frac{(y-2 z)^{2}}{r_{\mathrm{f}} l_{\mathrm{c}}}-2 \frac{\tau_{\mathrm{i}}}{E_{\mathrm{f}}} \frac{\left(l_{\mathrm{c}} / 2-2 y+2 z\right)^{2}}{r_{\mathrm{f}} l_{\mathrm{c}}}-\left(\alpha_{\mathrm{c}}-\alpha_{\mathrm{f}}\right) \Delta \mathrm{T}
\end{gathered}
$$

\subsection{Matrix Cracking Mode 5}

For matrix cracking mode 5, the fiber axial stress distribution upon unloading is determined by Equation (8):

$$
\left\{\begin{array}{l}
\sigma_{\mathrm{f}}(x)=\frac{1}{V_{\mathrm{f} \_a x i a l}}\left(\sigma-k \sigma_{\mathrm{to}}\right)+\frac{2 \tau_{\mathrm{i}}}{r_{\mathrm{f}}} x, x \in(0, y) \\
\sigma_{\mathrm{f}}(x)=\frac{1}{V_{\mathrm{f} \_a x i a l}}\left(\sigma-k \sigma_{\mathrm{to}}\right)+\frac{2 \tau_{\mathrm{i}}}{r_{\mathrm{f}}}(2 y-x), x \in\left(y, l_{\mathrm{d}}\right) \\
\sigma_{\mathrm{f}}(x)=\sigma_{\mathrm{fo}}+\left[\frac{1}{V_{\mathrm{f} \_ \text {axial }}}\left(\sigma-k \sigma_{\mathrm{to}}\right)+\frac{2 \tau_{\mathrm{i}}}{r_{\mathrm{f}}}\left(2 y-l_{\mathrm{d}}\right)-\sigma_{\mathrm{fo}}\right] \exp \left(-\rho \frac{x-l_{\mathrm{d}}}{r_{\mathrm{f}}}\right), x \in\left(l_{\mathrm{d}}, l_{c} / 2\right)
\end{array}\right.
$$

where $k$ denotes the proportion of transverse yarns in the entire composite. 
Upon reloading, the fiber axial stress distribution when the interface partially debonds is determined by Equation (9):

$$
\left\{\begin{array}{l}
\sigma_{\mathrm{f}}(x)=\frac{1}{V_{\mathrm{f}_{\mathrm{a}} \text { axial }}}\left(\sigma-k \sigma_{\mathrm{to}}\right)-\frac{2 \tau_{\mathrm{i}}}{r_{\mathrm{f}}} x, x \in(0, z) \\
\sigma_{f}(x)=\frac{1}{V_{\mathrm{f} \_ \text {axial }}}\left(\sigma-k \sigma_{\mathrm{to}}\right)+\frac{2 \tau_{\mathrm{i}}}{r_{\mathrm{f}}}(x-2 z), x \in(z, y) \\
\sigma_{\mathrm{f}}(x)=\frac{1}{V_{\mathrm{f} \_ \text {axial }}}\left(\sigma-k \sigma_{\mathrm{to}}\right)-\frac{2 \tau_{\mathrm{i}}}{r_{\mathrm{f}}}(x-2 y+2 z), x \in\left(y, l_{\mathrm{d}}\right) \\
\sigma_{\mathrm{f}}(x)=\sigma_{\mathrm{fo}}+\left[\frac{1}{V_{\mathrm{f} \_ \text {axial }}}\left(\sigma-k \sigma_{\mathrm{to}}\right)-\frac{2 \tau_{\mathrm{i}}}{r_{\mathrm{f}}}\left(l_{\mathrm{d}}-2 y+2 z\right)-\sigma_{\mathrm{fo}}\right] \exp \left(-\rho \frac{x-l_{\mathrm{d}}}{r_{\mathrm{f}}}\right), x \in\left(l_{\mathrm{d}}, l_{c} / 2\right)
\end{array}\right.
$$

Substituting Equations (8) and (9) into Equation (3), the unloading and reloading strains when the interface partially debonds are determined by Equations (10) and (11):

$$
\begin{gathered}
\mathcal{E}_{\mathrm{cu}}=\frac{1}{V_{\mathrm{f} \_ \text {axial }} E_{\mathrm{f}}}\left(\sigma-k \sigma_{\mathrm{to}}\right)+4 \frac{\tau_{\mathrm{i}}}{E_{\mathrm{f}}} \frac{y^{2}}{r_{\mathrm{f}} l_{\mathrm{c}}}-2 \frac{\tau_{\mathrm{i}}}{E_{\mathrm{f}}} \frac{\left(2 y-l_{\mathrm{d}}\right)\left(2 y+l_{\mathrm{d}}-l_{\mathrm{c}}\right)}{r_{\mathrm{f}} l_{\mathrm{c}}}-\left(\alpha_{\mathrm{c}}-\alpha_{\mathrm{f}}\right) \Delta \mathrm{T} \\
\varepsilon_{\mathrm{cr}}=\frac{1}{V_{\mathrm{f} \_ \text {axial }} E_{\mathrm{f}}}\left(\sigma-k \sigma_{\mathrm{to}}\right)-4 \frac{\tau_{\mathrm{i}}}{E_{\mathrm{f}}} \frac{z^{2}}{r_{\mathrm{f}} l_{\mathrm{c}}}+\frac{4 \tau_{\mathrm{i}}}{E_{\mathrm{f}}} \frac{(y-2 z)^{2}}{r_{\mathrm{f}} l_{\mathrm{c}}}+2 \frac{\tau_{\mathrm{i}}}{E_{\mathrm{f}}} \frac{\left(l_{\mathrm{d}}-2 y+2 z\right)\left(l_{\mathrm{d}}+2 y-2 z-l_{\mathrm{c}}\right)}{r_{\mathrm{f}} l_{\mathrm{c}}}-\left(\alpha_{c}-\alpha_{\mathrm{f}}\right) \Delta \mathrm{T}
\end{gathered}
$$

when the interface completely debonds, the unloading and reloading strains are determined by Equations (12) and (13):

$$
\begin{gathered}
\varepsilon_{\mathrm{cu}}=\frac{1}{V_{\mathrm{f} \_ \text {axial }} E_{\mathrm{f}}}\left(\sigma-k \sigma_{\mathrm{to}}\right)+4 \frac{\tau_{\mathrm{i}}}{E_{\mathrm{f}}} \frac{y^{2}}{r_{\mathrm{f}} l_{\mathrm{c}}}-2 \frac{\tau_{\mathrm{i}}}{E_{\mathrm{f}}} \frac{\left(2 y-l_{\mathrm{c}} / 2\right)^{2}}{r_{\mathrm{f}} l_{\mathrm{c}}}-\left(\alpha_{\mathrm{c}}-\alpha_{\mathrm{f}}\right) \Delta \mathrm{T} \\
\varepsilon_{\mathrm{cu}}=\frac{1}{V_{\mathrm{f} \_ \text {axial }} E_{\mathrm{f}}}\left(\sigma-k \sigma_{\mathrm{to}}\right)-4 \frac{\tau_{\mathrm{i}}}{E_{\mathrm{f}}} \frac{z^{2}}{r_{\mathrm{f}} l_{\mathrm{c}}}+4 \frac{\tau_{\mathrm{i}}}{E_{\mathrm{f}}} \frac{(y-2 z)^{2}}{r_{\mathrm{f}} l_{\mathrm{c}}}-2 \frac{\tau_{\mathrm{i}}}{E_{\mathrm{f}}} \frac{\left(l_{\mathrm{c}} / 2-2 y+2 z\right)^{2}}{r_{\mathrm{f}} l_{\mathrm{c}}}-\left(\alpha_{\mathrm{c}}-\alpha_{\mathrm{f}}\right) \Delta \mathrm{T}
\end{gathered}
$$

Considering the effect of multiple matrix cracking modes on hysteresis loops of 2D woven CMCs, the unloading and reloading strains of the composite are determined by Equations (14) and (15):

$$
\begin{aligned}
\left(\varepsilon_{\mathrm{u}}\right)_{\mathrm{c}} & =\eta\left(\varepsilon_{\mathrm{cu}}\right)_{3}+(1-\eta)\left(\varepsilon_{\mathrm{cu}}\right)_{5} \\
\left(\varepsilon_{\mathrm{r}}\right)_{\mathrm{c}} & =\eta\left(\varepsilon_{\mathrm{cr}}\right)_{3}+(1-\eta)\left(\varepsilon_{\mathrm{cr}}\right)_{5}
\end{aligned}
$$

where $\left(\varepsilon_{\mathrm{u}}\right)_{\mathrm{c}}$ and $\left(\varepsilon_{\mathrm{r}}\right)_{\mathrm{c}}$ denote the unloading and reloading strain of the composite, respectively; $\left(\varepsilon_{\mathrm{cu}}\right)_{3}$ and $\left(\varepsilon_{\mathrm{cr}}\right)_{3}$ denote the unloading and reloading strain of the matrix cracking mode 3 , respectively; $\left(\varepsilon_{\mathrm{cu}}\right)_{5}$ and $\left(\varepsilon_{\mathrm{cr}}\right)_{5}$ denote the unloading and reloading strain of the matrix cracking mode 5 , respectively; and $\eta$ is the damage parameter determined by the composite's damage condition, i.e., the proportion of matrix cracking mode 3 in the entire of matrix cracking modes of the composite, $\eta \in[0,1]$.

\section{Experimental Comparisons}

\subsection{Tension-Tension Fatigue Hysteresis Loops at $1000^{\circ} \mathrm{C}$ in Steam}

Michael [26] investigated the tension-tension cyclic fatigue behavior of $2 \mathrm{D}$ woven $\mathrm{SiC} / \mathrm{SiC}$ composite at $1000{ }^{\circ} \mathrm{C}$ in steam. The fatigue tests were conducted at the loading frequency of $f=1.0 \mathrm{~Hz}$ with a stress ratio of 0.1. The material properties of $2 \mathrm{D} \mathrm{SiC} / \mathrm{SiC}$ composite are given by [26]: $V_{\mathrm{f}}=21.5 \%$, $E_{\mathrm{f}}=150 \mathrm{GPa}, E_{\mathrm{m}}=60 \mathrm{GPa}, r_{\mathrm{f}}=\mathrm{v} 7.5 \mu \mathrm{m}, \zeta_{\mathrm{d}}=0.1 \mathrm{~J} / \mathrm{m}^{2}, \alpha_{\mathrm{f}}=4.6 \times 10^{-6} /{ }^{\circ} \mathrm{C}, \alpha_{\mathrm{m}}=4.38 \times 10^{-6} /{ }^{\circ} \mathrm{C}$, and $\Delta \mathrm{T}=-400^{\circ} \mathrm{C}$.

When $\sigma_{\max }=60 \mathrm{MPa}$, the experimental and theoretical hysteresis loops, and the interface slip of matrix cracking modes 3 and 5 corresponding to cycle number $N=2,10,000,100,000,150,000$, and 190,000 are illustrated in Figures 2-6. When $N=2$, the hysteresis loops of matrix cracking modes 3 mode 5, the composite and experimental data are given in Figure 2a, in which the proportion of matrix cracking mode 3 is $\eta=0.2$. For matrix cracking mode 3 , the hysteresis loops correspond to interface 
slip Case 2, as shown in Figure 2b. Upon unloading to the valley stress, the interface counter-slip length approaches $56.6 \%$ of the interface debonded length, i.e., $y\left(\sigma_{\min }\right) / l_{\mathrm{d}}=56.6 \%$; and upon reloading to the peak stress, the interface new slip length approaches $56.6 \%$ of the interface debonded length, i.e., $z\left(\sigma_{\max }\right) / l_{\mathrm{d}}=56.6 \%$. For matrix cracking mode 5, the hysteresis loops correspond to interface slip Case 2, as shown in Figure 2b. Upon unloading to the valley stress, the interface counter-slip length approaches $79 \%$ of the interface debonded length, i.e., $y\left(\sigma_{\min }\right) / l_{\mathrm{d}}=79 \%$; and upon reloading to the peak stress, the interface new slip length approaches $79 \%$ of the interface debonded length, i.e., $z\left(\sigma_{\max }\right) / l_{\mathrm{d}}=79 \%$.
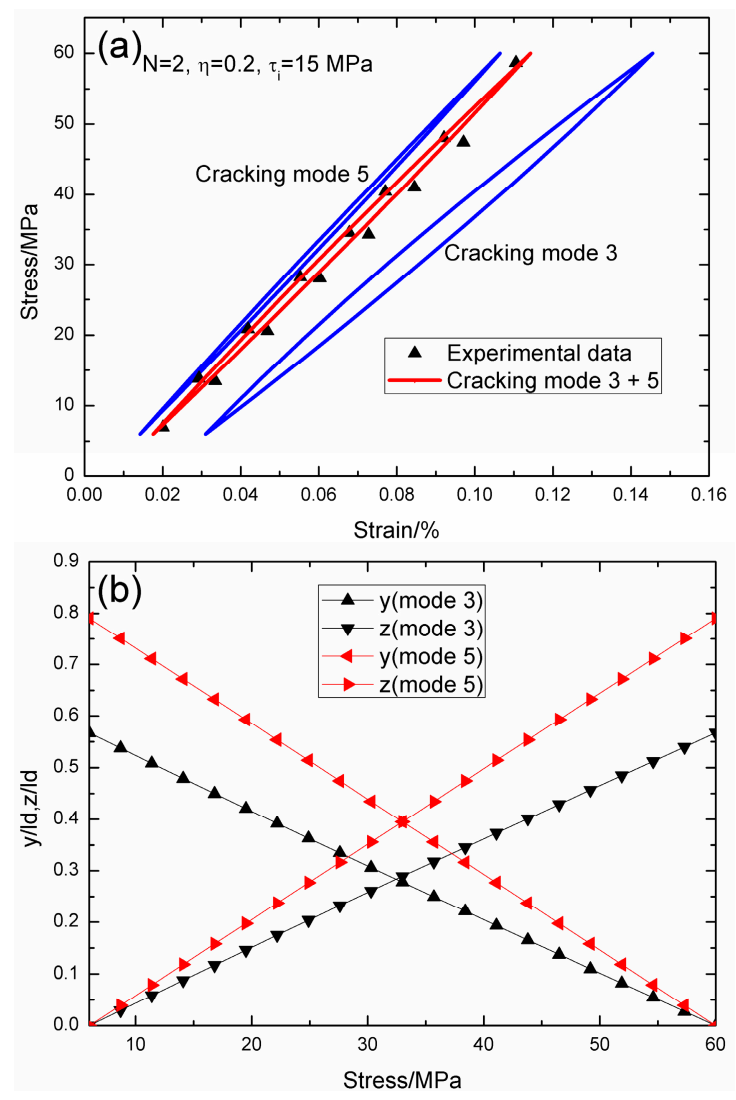

Figure 2. (a) The theoretical and experimental hysteresis loops; and (b) the interface slip lengths, i.e., $y / l_{\mathrm{d}}$ and $z / l_{\mathrm{d}}$, of matrix cracking modes 3 and 5 of $2 \mathrm{D}$ woven $\mathrm{SiC} / \mathrm{SiC}$ composite under $\sigma_{\max }=60 \mathrm{MPa}$ at $1000{ }^{\circ} \mathrm{C}$ in steam and a loading frequency of $1.0 \mathrm{~Hz}$ when $N=2$.

When $N=10,000$, the hysteresis loops of matrix cracking modes 3 and 5 , and the composite and experimental data are given in Figure 3a, in which the proportion of matrix cracking mode 3 is $\eta=0.2$. For matrix cracking mode 3, the hysteresis loops correspond to interface slip Case 2, as shown in Figure $3 \mathrm{~b}$. Upon unloading to the valley stress, the interface counter-slip length approaches $55.8 \%$ of the interface debonded length, i.e., $y\left(\sigma_{\min }\right) / l_{\mathrm{d}}=55.8 \%$; and upon reloading to the peak stress, the interface new slip length approaches $55.8 \%$ of the interface debonded length, i.e., $z\left(\sigma_{\max }\right) / l_{\mathrm{d}}=55.8 \%$. For matrix cracking mode 5, the hysteresis loops correspond to interface slip Case 2, as shown in Figure $3 \mathrm{~b}$. Upon unloading to the valley stress, the interface counter-slip length approaches $75.6 \%$ of the interface debonded length, i.e., $y\left(\sigma_{\min }\right) / l_{\mathrm{d}}=75.6 \%$; and upon reloading to the peak stress, the interface new slip length approaches $75.6 \%$ of the interface debonded length, i.e., $z\left(\sigma_{\max }\right) / l_{\mathrm{d}}=75.6 \%$. 

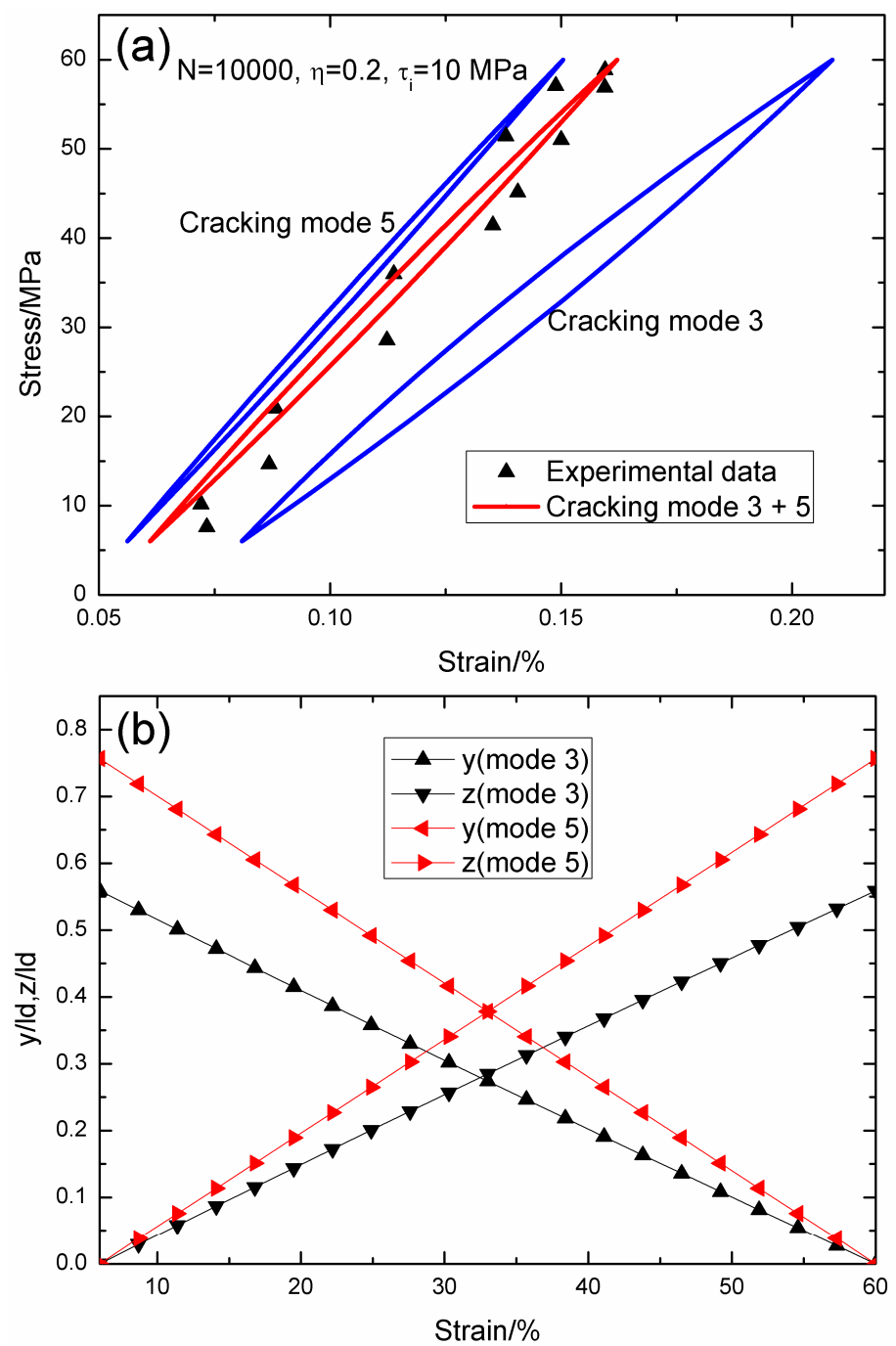

Figure 3. (a) The theoretical and experimental hysteresis loops; and (b) the interface slip lengths, i.e., $y / l_{\mathrm{d}}$ and $z / l_{\mathrm{d}}$, of matrix cracking modes 3 and 5 of $2 \mathrm{D}$ woven $\mathrm{SiC} / \mathrm{SiC}$ composite under $\sigma_{\max }=60 \mathrm{MPa}$ at $1000{ }^{\circ} \mathrm{C}$ in steam and a loading frequency of $1.0 \mathrm{~Hz}$ when $N=10,000$.

When $N=100,000$, the hysteresis loops of matrix cracking modes 3 and 5, and the composite and experimental data are given in Figure $4 a$, in which the proportion of matrix cracking mode 3 is $\eta=0.2$. For matrix cracking mode 3 , the hysteresis loops correspond to interface slip Case 2, as shown in Figure $4 \mathrm{~b}$. Upon unloading to the valley stress, the interface counter-slip length approaches $55.5 \%$ of the interface debonded length, i.e., $y\left(\sigma_{\min }\right) / l_{\mathrm{d}}=55.5 \%$; and upon reloading to the peak stress, the interface new slip length approaches $55.5 \%$ of the interface debonded length, i.e., $z\left(\sigma_{\max }\right) / l_{\mathrm{d}}=55.5 \%$. For matrix cracking mode 5, the hysteresis loops correspond to interface slip Case 2, as shown in Figure $4 \mathrm{~b}$. Upon unloading to the valley stress, the interface counter-slip length approaches $74.4 \%$ of the interface debonded length, i.e., $y\left(\sigma_{\min }\right) / l_{\mathrm{d}}=74.4 \%$; and upon reloading to the peak stress, the interface new slip length approaches $74.4 \%$ of the interface debonded length, i.e., $z\left(\sigma_{\max }\right) / l_{\mathrm{d}}=74.4 \%$. 

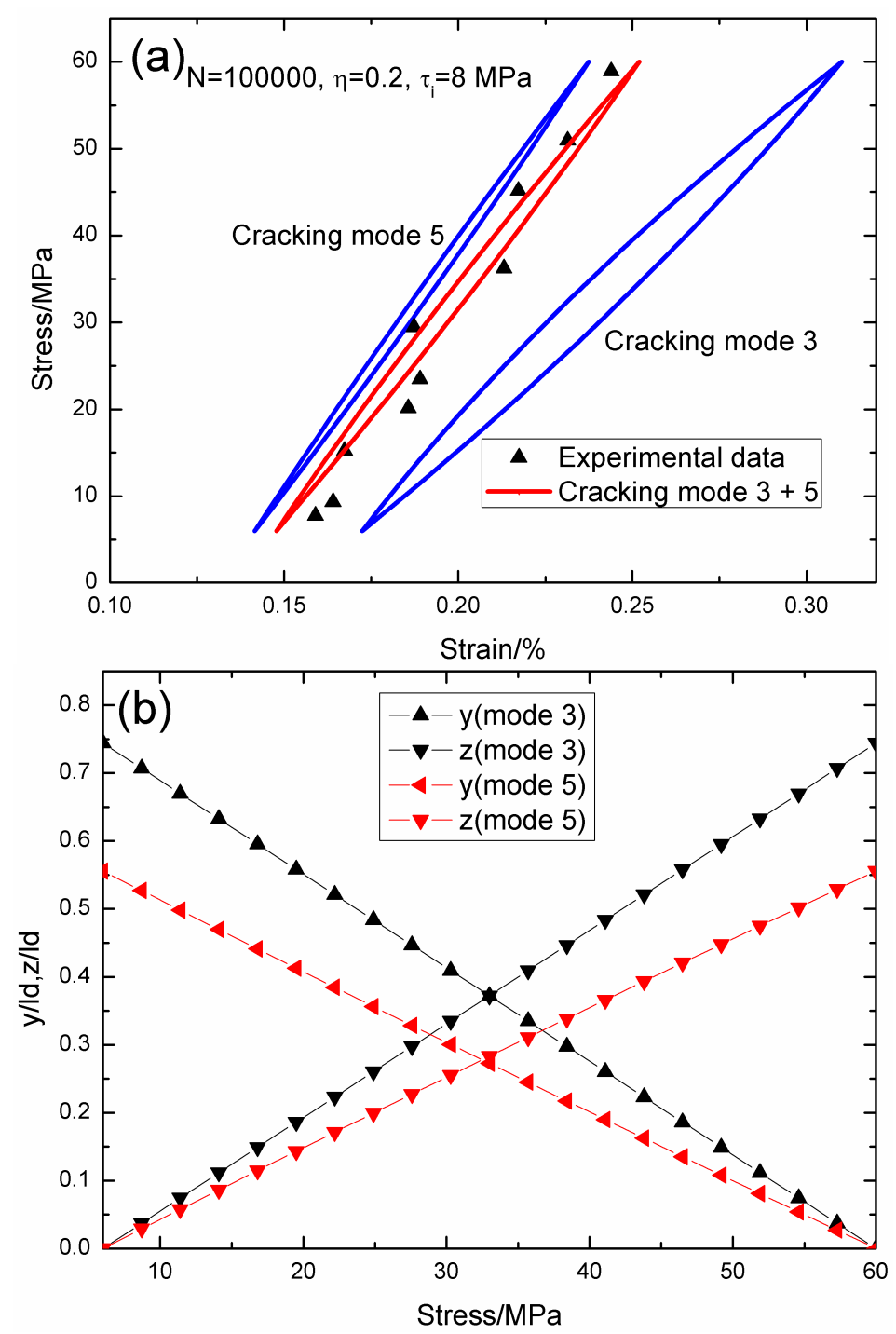

Figure 4. (a) The theoretical and experimental hysteresis loops; and (b) the interface slip lengths, i.e., $y / l_{\mathrm{d}}$ and $z / l_{\mathrm{d}}$, of matrix cracking modes 3 and 5 of $2 \mathrm{D}$ woven $\mathrm{SiC} / \mathrm{SiC}$ composite under $\sigma_{\max }=60 \mathrm{MPa}$ at $1000{ }^{\circ} \mathrm{C}$ in steam and a loading frequency of $1.0 \mathrm{~Hz}$ when $N=100,000$.

When $N=150,000$, the hysteresis loops of matrix cracking modes 3 and 5, and the composite and experimental data are given in Figure 5a, in which the proportion of matrix cracking mode 3 is $\eta=0.2$. For matrix cracking mode 3 , the hysteresis loops correspond to interface slip Case 2, as shown in Figure 5b. Upon unloading to the valley stress, the interface counter-slip length approaches $55.1 \%$ of the interface debonded length, i.e., $y\left(\sigma_{\min }\right) / l_{\mathrm{d}}=55.1 \%$; and upon reloading to the peak stress, the interface new slip length approaches $55.1 \%$ of the interface debonded length, i.e., $z\left(\sigma_{\max }\right) / l_{\mathrm{d}}=55.1 \%$. For matrix cracking mode 5, the hysteresis loops correspond to interface slip Case 2, as shown in Figure $5 \mathrm{~b}$. Upon unloading to the valley stress, the interface counter-slip length approaches $72.7 \%$ of the interface debonded length, i.e., $y\left(\sigma_{\min }\right) / l_{\mathrm{d}}=72.7 \%$; and upon reloading to the peak stress, the interface new slip length approaches $72.7 \%$ of the interface debonded length, i.e., $z\left(\sigma_{\max }\right) / l_{\mathrm{d}}=72.7 \%$. 

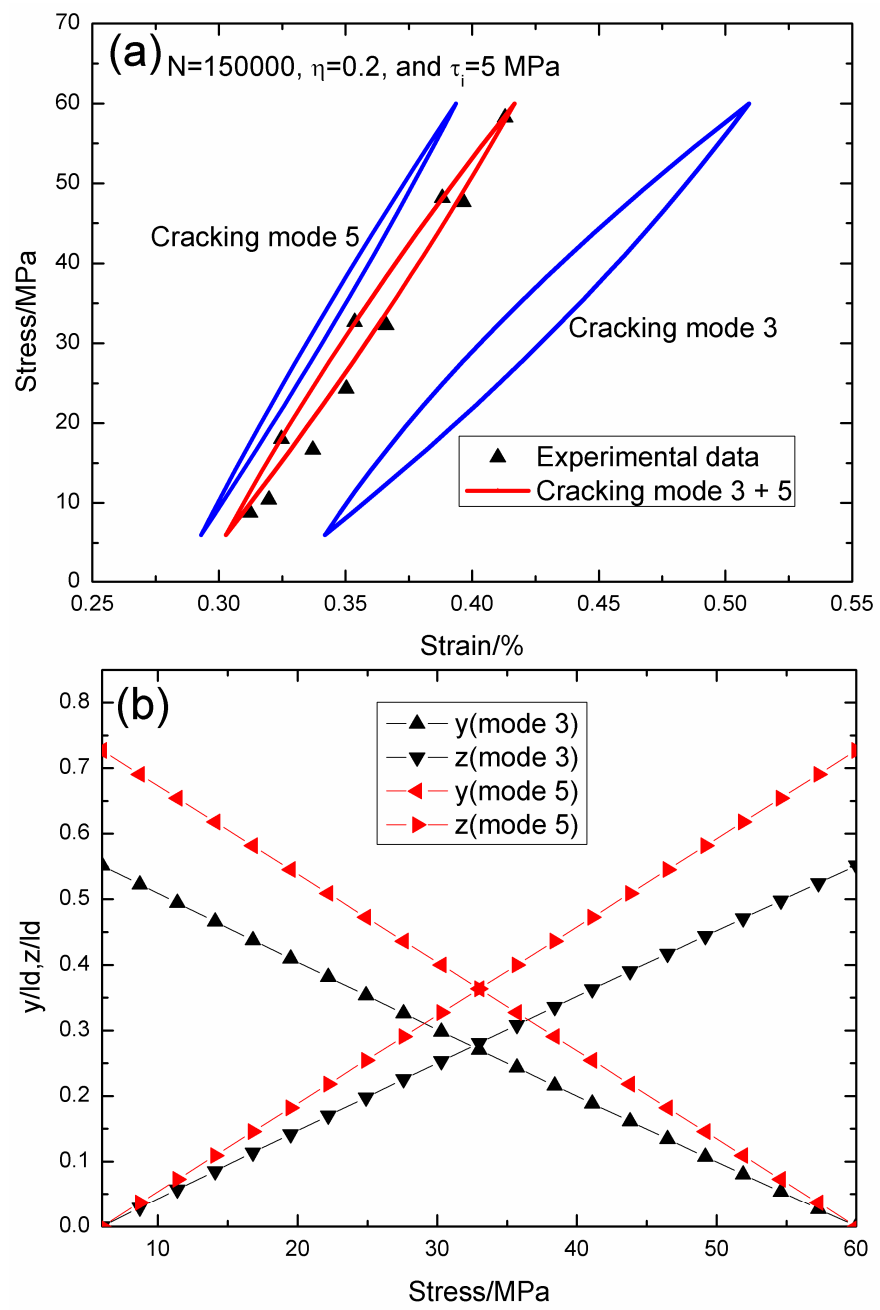

Figure 5. (a) The theoretical and experimental hysteresis loops; and (b) the interface slip lengths, i.e., $y / l_{\mathrm{d}}$ and $z / l_{\mathrm{d}}$, of matrix cracking modes 3 and 5 of $2 \mathrm{D}$ woven $\mathrm{SiC} / \mathrm{SiC}$ composite under $\sigma_{\max }=60 \mathrm{MPa}$ at $1000{ }^{\circ} \mathrm{C}$ in steam and a loading frequency of $1.0 \mathrm{~Hz}$ when $N=150,000$.

When $N=190,000$, the hysteresis loops of matrix cracking modes 3 and 5, and the composite and experimental data are given in Figure 6a, in which the proportion of matrix cracking mode 3 is $\eta=0.2$. For matrix cracking mode 3 , the hysteresis loops correspond to interface slip Case 3 , as shown in Figure $6 \mathrm{~b}$. Upon unloading to the valley stress, the interface counter-slip length approaches $60.6 \%$ of the interface debonded length, i.e., $y\left(\sigma_{\min }\right) / l_{\mathrm{d}}=60.6 \%$; and upon reloading to the peak stress, the interface new slip length approaches $60.6 \%$ of the interface debonded length, i.e., $z\left(\sigma_{\max }\right) / l_{\mathrm{d}}=60.6 \%$. For matrix cracking mode 5, the hysteresis loops correspond to interface slip Case 2, as shown in Figure $6 \mathrm{~b}$. Upon unloading to the valley stress, the interface counter-slip length approaches $71.6 \%$ of the interface debonded length, i.e., $y\left(\sigma_{\min }\right) / l_{\mathrm{d}}=71.6 \%$; and upon reloading to the peak stress, the interface new slip length approaches $71.6 \%$ of the interface debonded length, i.e., $z\left(\sigma_{\max }\right) / l_{\mathrm{d}}=71.6 \%$. 

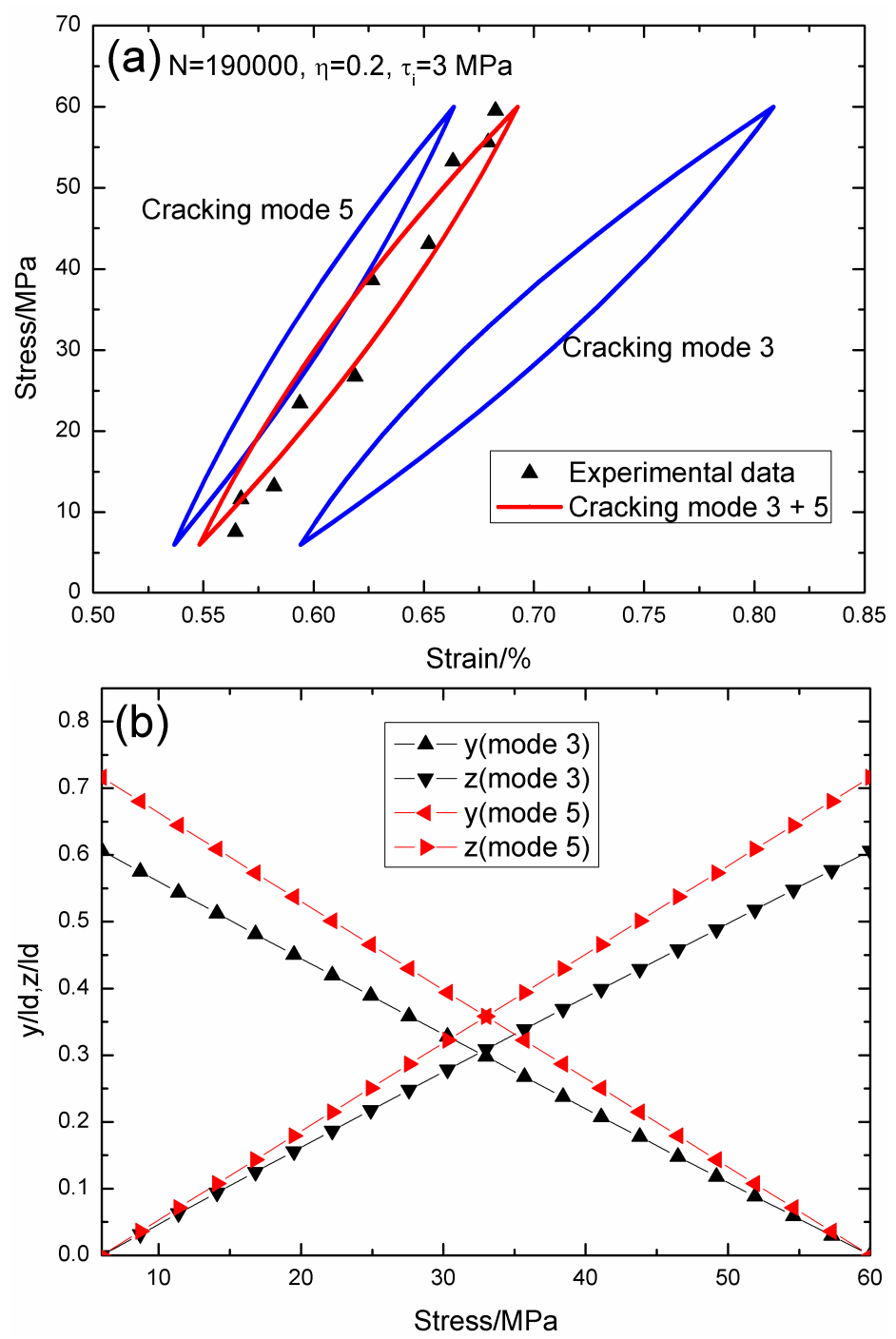

Figure 6. (a) The theoretical and experimental hysteresis loops; and (b) the interface slip lengths, i.e., $y / l_{\mathrm{d}}$ and $z / l_{\mathrm{d}}$, of matrix cracking modes 3 and 5 of $2 \mathrm{D}$ woven $\mathrm{SiC} / \mathrm{SiC}$ composite under $\sigma_{\max }=60 \mathrm{MPa}$ at $1000{ }^{\circ} \mathrm{C}$ in steam and a loading frequency of $1.0 \mathrm{~Hz}$ when $N=190,000$.

When $\sigma_{\max }=100 \mathrm{MPa}$, the experimental and theoretical hysteresis loops, and the interface slip of matrix cracking modes 3 and 5 corresponding to cycle number $N=2,500,3000$ and 10,000 are illustrated in Figures 7-10. When $N=2$, the hysteresis loops of matrix cracking modes 3 and 5, and the composite and experimental data are given in Figure 7a, in which the proportion of matrix cracking mode 3 is $\eta=0.4$. For matrix cracking mode 3 , the hysteresis loops correspond to interface slip Case 2, as shown in Figure $7 \mathrm{~b}$. Upon unloading to the valley stress, the interface counter-slip length approaches $51.2 \%$ of the interface debonded length, i.e., $y\left(\sigma_{\min }\right) / l_{\mathrm{d}}=51.2 \%$; and upon reloading to the peak stress, the interface new slip length approaches $51.2 \%$ of the interface debonded length, i.e., $z\left(\sigma_{\max }\right) / l_{\mathrm{d}}=51.2 \%$. For matrix cracking mode 5 , the hysteresis loops correspond to interface slip Case 2, as shown in Figure $7 \mathrm{~b}$. Upon unloading to the valley stress, the interface counter-slip length approaches $60.6 \%$ of the interface debonded length, i.e., $y\left(\sigma_{\min }\right) / l_{\mathrm{d}}=60.6 \%$; and upon reloading to the peak stress, the interface new slip length approaches $60.6 \%$ of the interface debonded length, i.e., $z\left(\sigma_{\max }\right) / l_{\mathrm{d}}=60.6 \%$. 

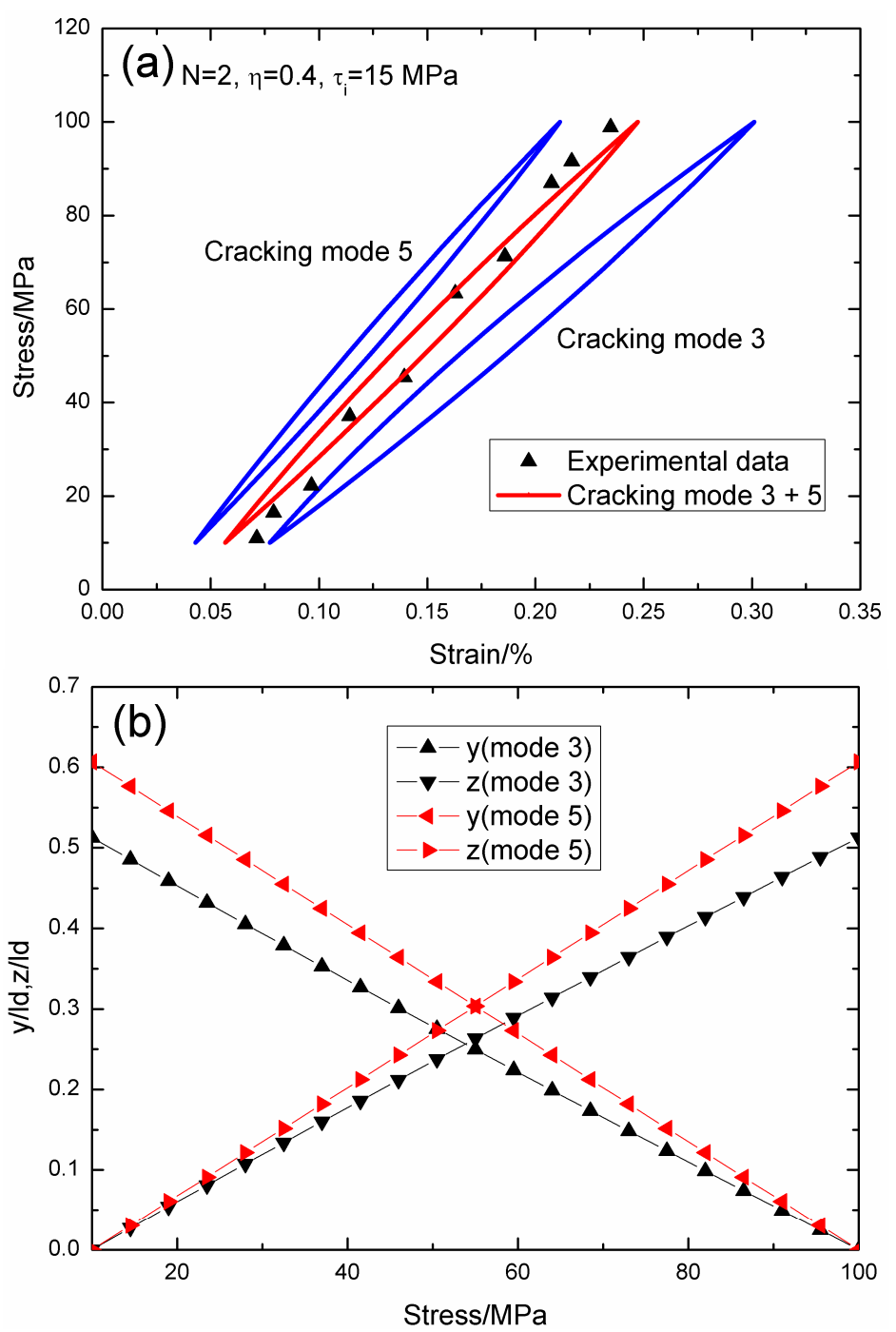

Figure 7. (a) The theoretical and experimental hysteresis loops; and (b) the interface slip lengths, i.e., $y / l_{\mathrm{d}}$ and $z / l_{\mathrm{d}}$, of matrix cracking modes 3 and 5 of $2 \mathrm{D}$ woven $\mathrm{SiC} / \mathrm{SiC}$ composite under $\sigma_{\max }=100 \mathrm{MPa}$ at $1000^{\circ} \mathrm{C}$ in steam and a loading frequency of $1.0 \mathrm{~Hz}$ when $N=2$.

When $N=500$, the hysteresis loops of matrix cracking modes 3 and 5 , and the composite and experimental data are given in Figure 8a, in which the proportion of matrix cracking mode 3 is $\eta=0.4$. For matrix cracking mode 3, the hysteresis loops correspond to interface slip Case 2, as shown in Figure $8 \mathrm{~b}$. Upon unloading to the valley stress, the interface counter-slip length approaches $51.1 \%$ of the interface debonded length, i.e., $y\left(\sigma_{\min }\right) / l_{\mathrm{d}}=51.1 \%$; and upon reloading to the peak stress, the interface new slip length approaches $51.1 \%$ of the interface debonded length, i.e., $z\left(\sigma_{\max }\right) / l_{\mathrm{d}}=51.1 \%$. For matrix cracking mode 5, the hysteresis loops correspond to interface slip Case 2, as shown in Figure $8 \mathrm{~b}$. Upon unloading to the valley stress, the interface counter-slip length approaches $60.1 \%$ of the interface debonded length, i.e., $y\left(\sigma_{\min }\right) / l_{\mathrm{d}}=60.1 \%$; and upon reloading to the peak stress, the interface new slip length approaches $60.1 \%$ of the interface debonded length, i.e., $z\left(\sigma_{\max }\right) / l_{\mathrm{d}}=60.1 \%$. 

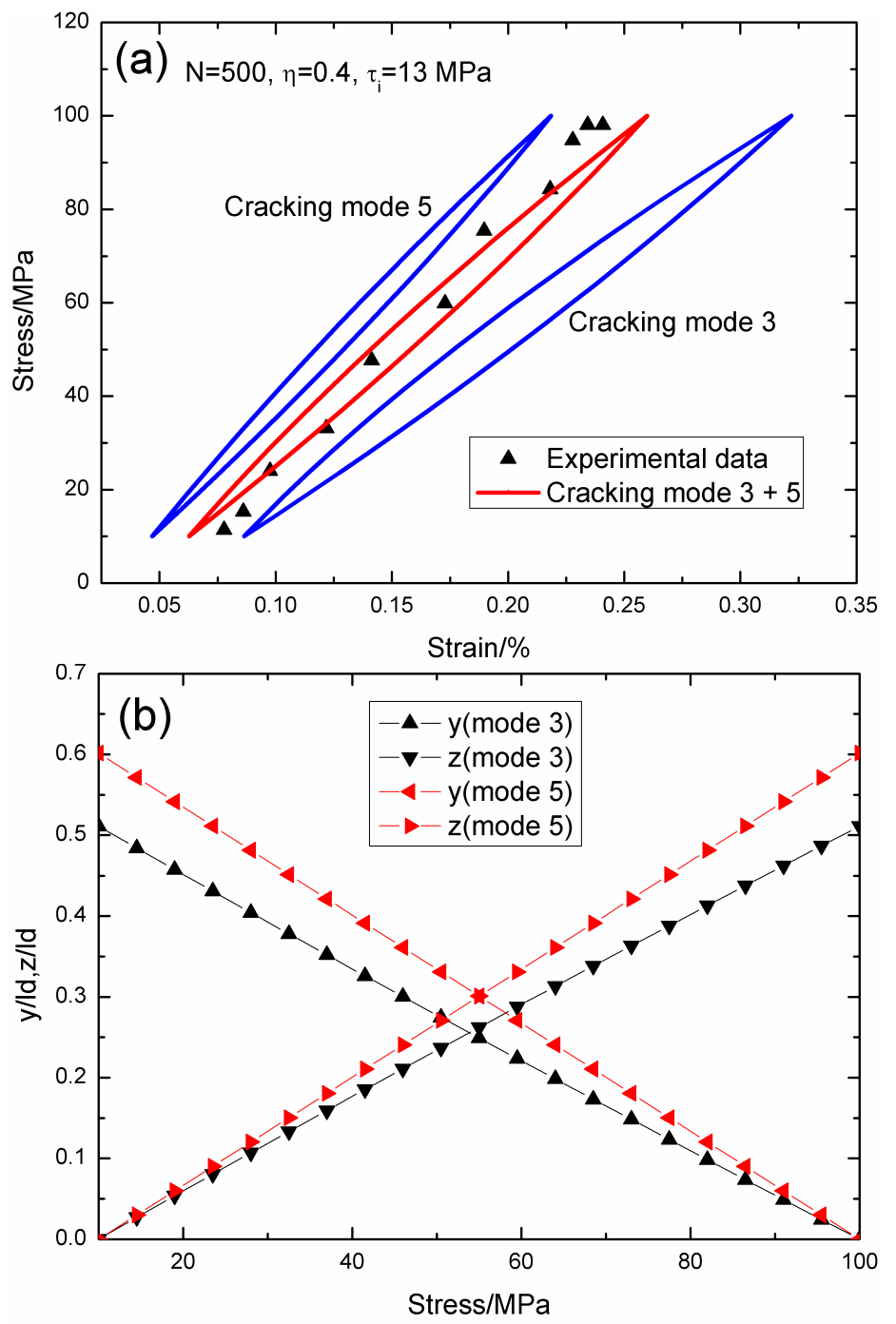

Figure 8. (a) The theoretical and experimental hysteresis loops; and (b) the interface slip lengths, i.e., $y / l_{\mathrm{d}}$ and $z / l_{\mathrm{d}}$, of matrix cracking modes 3 and 5 of $2 \mathrm{D}$ woven $\mathrm{SiC} / \mathrm{SiC}$ composite under $\sigma_{\max }=100 \mathrm{MPa}$ at $1000{ }^{\circ} \mathrm{C}$ in air and a loading frequency of $1.0 \mathrm{~Hz}$ when $N=500$.

When $N=3000$, the hysteresis loops of matrix cracking mode 3 and mode 5 , the composite and experimental data are given in Figure 9a, in which the proportion of matrix cracking mode 3 is $\eta=0.4$. For matrix cracking mode 3, the hysteresis loops correspond to interface slip Case 2, as shown in Figure $9 \mathrm{~b}$. Upon unloading to the valley stress, the interface counter-slip length approaches $50.8 \%$ of the interface debonded length, i.e., $y\left(\sigma_{\min }\right) / l_{\mathrm{d}}=50.8 \%$; and upon reloading to the peak stress, the interface new slip length approaches $50.8 \%$ of the interface debonded length, i.e., $z\left(\sigma_{\max }\right) / l_{\mathrm{d}}=50.8 \%$. For matrix cracking mode 5, the hysteresis loops correspond to interface slip Case 2, as shown in Figure $9 \mathrm{~b}$. Upon unloading to the valley stress, the interface counter-slip length approaches $59.4 \%$ of the interface debonded length, i.e., $y\left(\sigma_{\mathrm{min}}\right) / l_{\mathrm{d}}=59.4 \%$; and upon reloading to the peak stress, the interface new slip length approaches $59.4 \%$ of the interface debonded length, i.e., $z\left(\sigma_{\max }\right) / l_{\mathrm{d}}=59.4 \%$. 

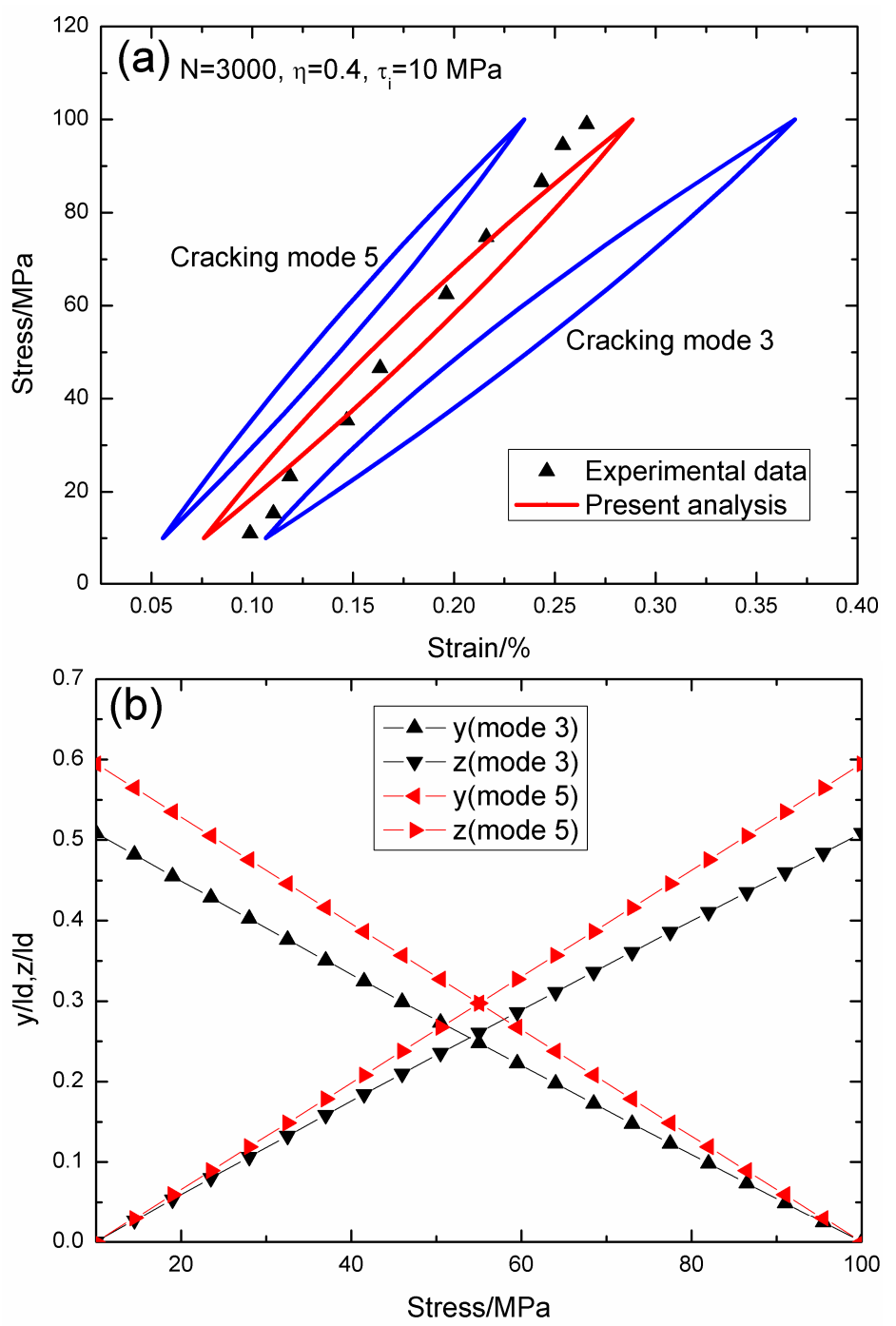

Figure 9. (a) The theoretical and experimental hysteresis loops; and (b) the interface slip lengths, i.e., $y / l_{\mathrm{d}}$ and $z / l_{\mathrm{d}}$, of matrix cracking modes 3 and 5 of $2 \mathrm{D}$ woven $\mathrm{SiC} / \mathrm{SiC}$ composite under $\sigma_{\max }=100 \mathrm{MPa}$ at $1000{ }^{\circ} \mathrm{C}$ in steam and a loading frequency of $1.0 \mathrm{~Hz}$ when $N=3000$.

When $N=10,000$, the hysteresis loops of matrix cracking modes 3 and 5 , and the composite and experimental data are given in Figure 10a, in which the proportion of matrix cracking mode 3 is $\eta=0.4$. For matrix cracking mode 3, the hysteresis loops correspond to interface slip Case 2, as shown in Figure 10b. Upon unloading to the valley stress, the interface counter-slip length approaches $50.7 \%$ of the interface debonded length, i.e., $y\left(\sigma_{\min }\right) / l_{\mathrm{d}}=50.7 \%$; and upon reloading to the peak stress, the interface new slip length approaches $50.7 \%$ of the interface debonded length, i.e., $z\left(\sigma_{\max }\right) / l_{\mathrm{d}}=50.7 \%$. For matrix cracking mode 5, the hysteresis loops correspond to interface slip Case 2, as shown in Figure 10b. Upon unloading to the valley stress, the interface counter-slip length approaches $58.9 \%$ of the interface debonded length, i.e., $y\left(\sigma_{\min }\right) / l_{\mathrm{d}}=58.9 \%$; and upon reloading to the peak stress, the interface new slip length approaches $58.9 \%$ of the interface debonded length, i.e., $z\left(\sigma_{\max }\right) / l_{\mathrm{d}}=58.9 \%$. 

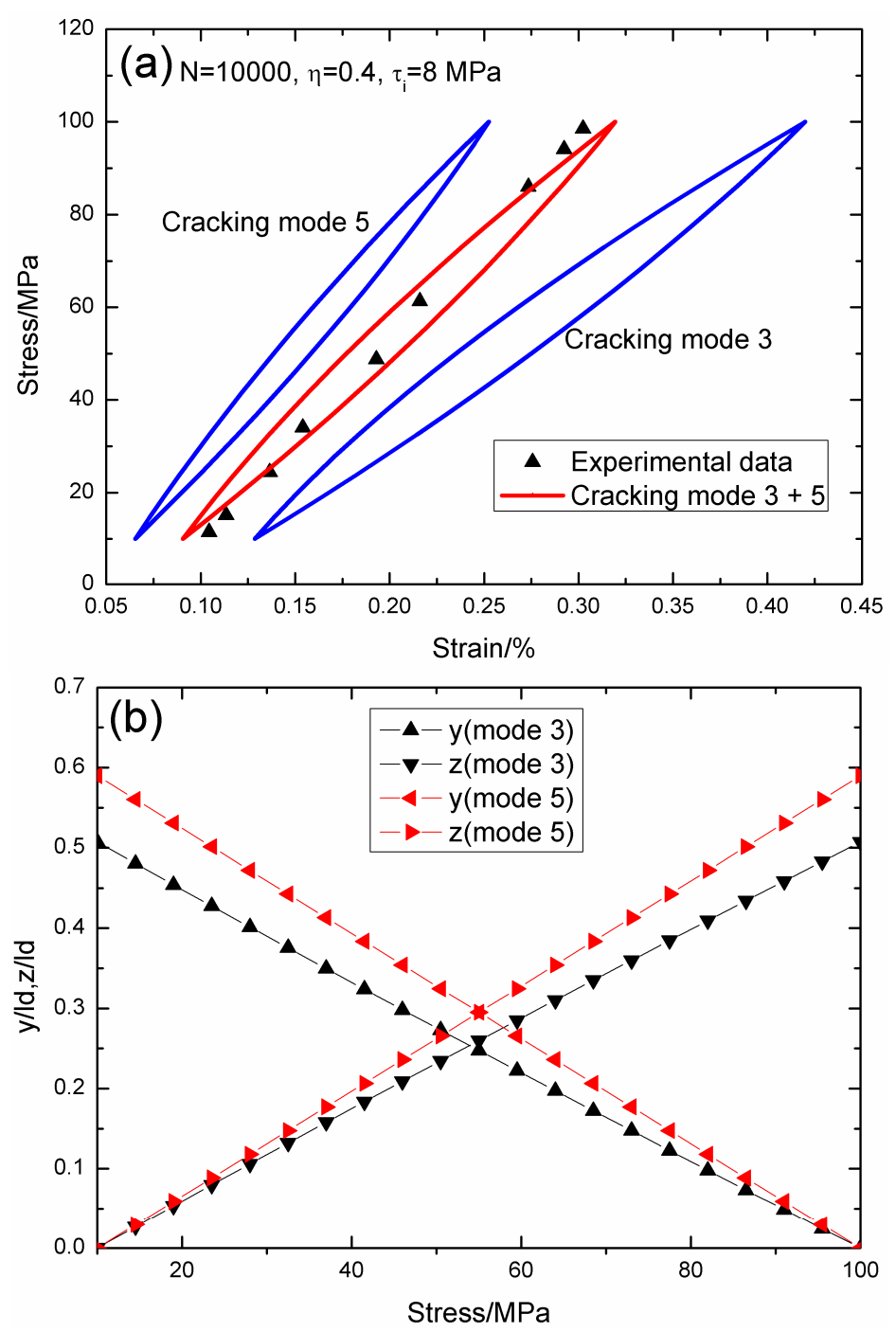

Figure 10. (a) The theoretical and experimental hysteresis loops; and (b) the interface slip lengths, i.e., $y / l_{\mathrm{d}}$ and $z / l_{\mathrm{d}}$, of matrix cracking modes 3 and 5 of $2 \mathrm{D}$ woven $\mathrm{SiC} / \mathrm{SiC}$ composite under $\sigma_{\max }=100 \mathrm{MPa}$ at $1000{ }^{\circ} \mathrm{C}$ in steam and a loading frequency of $1.0 \mathrm{~Hz}$ when $N=10,000$.

\subsection{Tension-Tension Fatigue Hysteresis Loops at $1200^{\circ} \mathrm{C}$ in Steam}

Jacob [27] investigated the tension-tension cyclic fatigue behavior of $2 \mathrm{D}$ woven $\mathrm{SiC} / \mathrm{SiC}$ composite at $1200{ }^{\circ} \mathrm{C}$ in steam. The fatigue tests were conducted at the loading frequency of $f=0.1$ and $1 \mathrm{~Hz}$ with a stress ratio of 0.05 . The material properties of $2 \mathrm{D} \mathrm{SiC} / \mathrm{SiC}$ composite are given by [27]: $V_{\mathrm{f}}=34.8 \%$, $E_{\mathrm{f}}=150 \mathrm{GPa}, E_{\mathrm{m}}=100 \mathrm{GPa}, r_{\mathrm{f}}=7.5 \mu \mathrm{m}, \zeta_{\mathrm{d}}=0.1 \mathrm{~J} / \mathrm{m}^{2}, \alpha_{\mathrm{f}}=4.6 \times 10^{-6} /{ }^{\circ} \mathrm{C}, \alpha_{\mathrm{m}}=4.38 \times 10^{-6} /{ }^{\circ} \mathrm{C}$, and $\Delta \mathrm{T}=-200^{\circ} \mathrm{C}$.

When $\sigma_{\max }=140 \mathrm{MPa}$ and $f=0.1 \mathrm{~Hz}$, the experimental and theoretical hysteresis loops, and the interface slip of matrix cracking modes 3 and 5 corresponding to cycle number $N=100,1000$ and 10,000 are illustrated in Figures 11-13. When $N=100$, the hysteresis loops of matrix cracking mode 3 and mode 5, and the composite and experimental data are given in Figure 11a, in which the proportion of matrix cracking mode 3 is $\eta=0.2$. For matrix cracking mode 3 , the hysteresis loops correspond to interface slip Case 2, as shown in Figure 11b. Upon unloading to the valley stress, the interface counter-slip length approaches $54.6 \%$ of the interface debonded length, i.e., $y\left(\sigma_{\min }\right) / l_{\mathrm{d}}=54.6 \%$; and upon reloading to the peak stress, the interface new slip length approaches $54.6 \%$ of the interface debonded length, i.e., $z\left(\sigma_{\max }\right) / l_{\mathrm{d}}=54.6 \%$. For matrix cracking mode 5 , the hysteresis loops correspond to interface slip Case 2, as shown in Figure 11b. Upon unloading to the valley stress, the interface 
counter-slip length approaches $72.8 \%$ of the interface debonded length, i.e., $y\left(\sigma_{\min }\right) / l_{\mathrm{d}}=72.8 \%$; and upon reloading to the peak stress, the interface new slip length approaches $72.8 \%$ of the interface debonded length, i.e., $z\left(\sigma_{\max }\right) / l_{\mathrm{d}}=72.8 \%$.
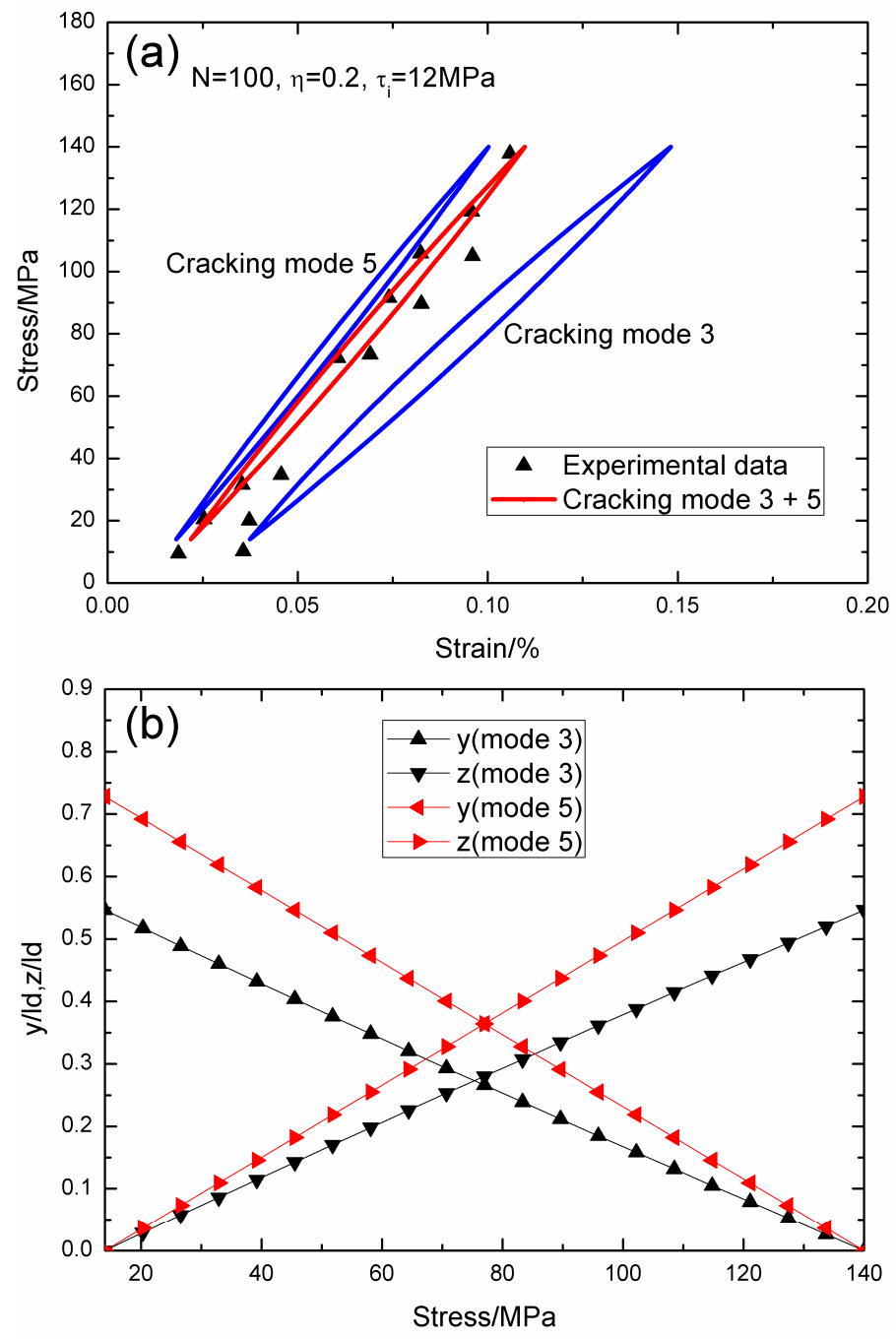

Figure 11. (a) The theoretical and experimental hysteresis loops; and (b) the interface slip lengths, i.e., $y / l_{\mathrm{d}}$ and $z / l_{\mathrm{d}}$, of matrix cracking modes 3 and 5 of $2 \mathrm{D}$ woven $\mathrm{SiC} / \mathrm{SiC}$ composite under $\sigma_{\max }=140 \mathrm{MPa}$ at $1200{ }^{\circ} \mathrm{C}$ in steam and a loading frequency of $0.1 \mathrm{~Hz}$ when $N=100$.

When $N=1000$, the hysteresis loops of matrix cracking mode 3 and mode 5 , and the composite and experimental data are given in Figure 12a, in which the proportion of matrix cracking mode 3 is $\eta=0.2$. For matrix cracking mode 3 , the hysteresis loops correspond to interface slip Case 4 , as shown in Figure 12b. Upon unloading, the interface counter-slip length approaches ttheo interface debonded length at $\sigma_{\mathrm{tr} \_\mathrm{fu}}=39.2 \mathrm{MPa}$, i.e., $y\left(\sigma_{\mathrm{tr} \_\mathrm{fu}}\right) / l_{\mathrm{d}}=1$; and upon reloading to $\sigma_{\mathrm{tr} \_\mathrm{fr}}=114.8 \mathrm{MPa}$, the interface new slip length approaches the interface debonded length, i.e., $z\left(\sigma_{\mathrm{tr} \_f r}\right) / l_{\mathrm{d}}=1$. For matrix cracking mode 5, the hysteresis loops correspond to interface slip Case 2, as shown in Figure $12 \mathrm{~b}$. Upon unloading to the valley stress, the interface counter-slip length approaches $71.3 \%$ of the interface debonded length, i.e., $y\left(\sigma_{\mathrm{min}}\right) / l_{\mathrm{d}}=71.3 \%$; and upon reloading to the peak stress, the interface new slip length approaches $71.3 \%$ of the interface debonded length, i.e., $z\left(\sigma_{\max }\right) / l_{\mathrm{d}}=71.3 \%$. 

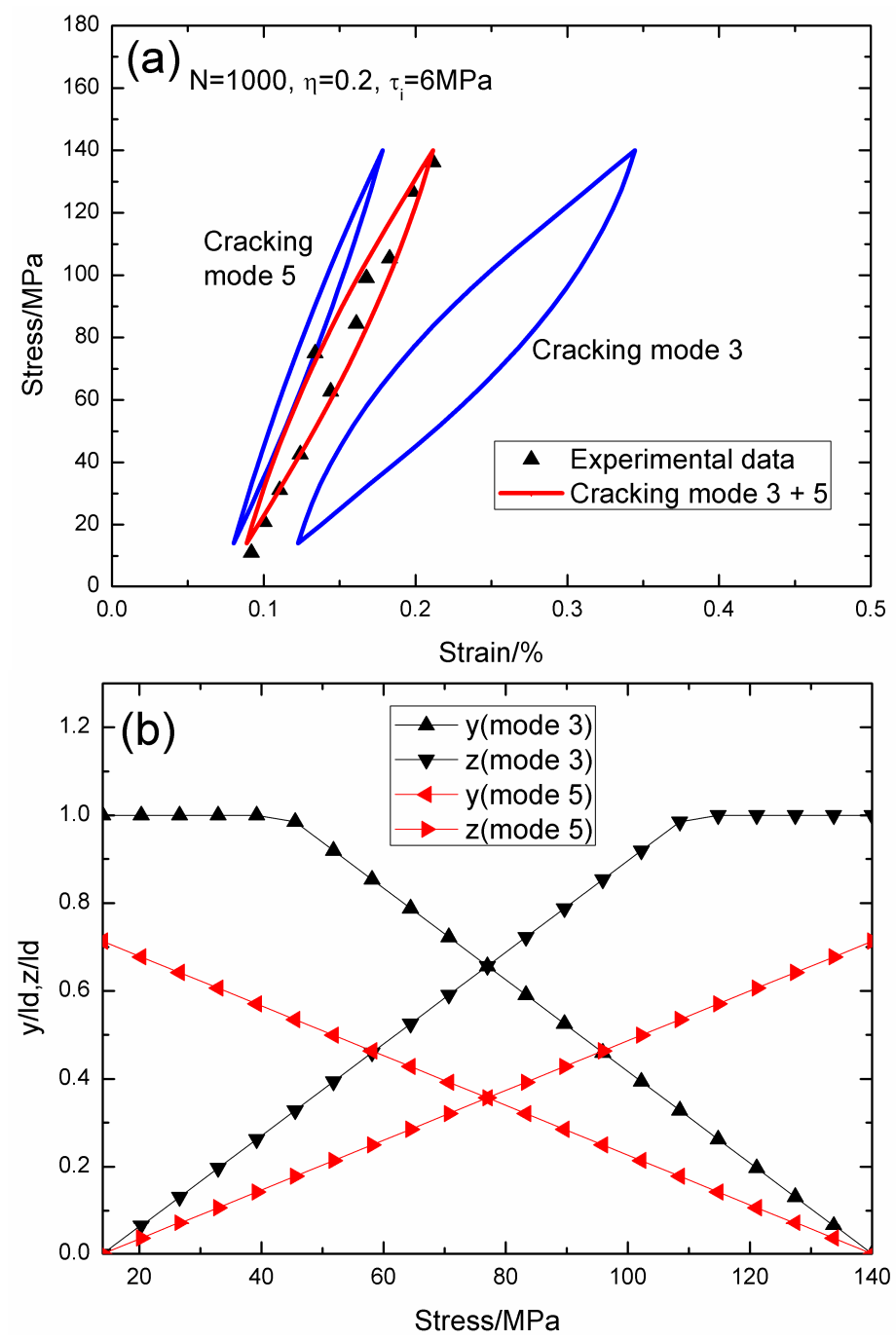

Figure 12. (a) The theoretical and experimental hysteresis loops; and (b) the interface slip lengths, i.e., $y / l_{\mathrm{d}}$ and $z / l_{\mathrm{d}}$, of matrix cracking modes 3 and 5 of $2 \mathrm{D}$ woven $\mathrm{SiC} / \mathrm{SiC}$ composite under $\sigma_{\max }=140 \mathrm{MPa}$ at $1200{ }^{\circ} \mathrm{C}$ in steam and a loading frequency of $0.1 \mathrm{~Hz}$ when $N=1000$.

When $N=10,000$, the hysteresis loops of matrix cracking mode 3 and mode 5 , and the composite and experimental data are given in Figure 13a, in which the proportion of matrix cracking mode 3 is $\eta=0.2$. For matrix cracking mode 3 , the hysteresis loops correspond to interface slip Case 4 , as shown in Figure 13b. Upon unloading, the interface counter-slip length approaches the interface debonded length at $\sigma_{\text {tr_fu }}=89.6 \mathrm{MPa}$, i.e., $y\left(\sigma_{\text {tr_fu }_{-}}\right) / l_{\mathrm{d}}=1$; and upon reloading to $\sigma_{\mathrm{tr}_{-} \text {fr }}=64.4 \mathrm{MPa}$, the interface new slip length approaches the interface debonded length, i.e., $z\left(\sigma_{\mathrm{tr} \_\mathrm{fr}}\right) / l_{\mathrm{d}}=1$. For matrix cracking mode 5 , the hysteresis loops correspond to interface slip Case 4, as shown in Figure 13b. Upon unloading, the interface counter-slip length approaches the interface debonded length $\operatorname{tat}_{\mathrm{tr} \text { fu }}=14 \mathrm{MPa}$, i.e., $y\left(\sigma_{\text {tr_fu }}\right) / l_{\mathrm{d}}=1$; and upon reloading to $\sigma_{\text {tr_fr }}=140 \mathrm{MPa}$, the interface new slip length approaches the interface debonded length, i.e., $z\left(\sigma_{\mathrm{tr}_{-} \mathrm{fr}}\right) / l_{\mathrm{d}}=1$. 

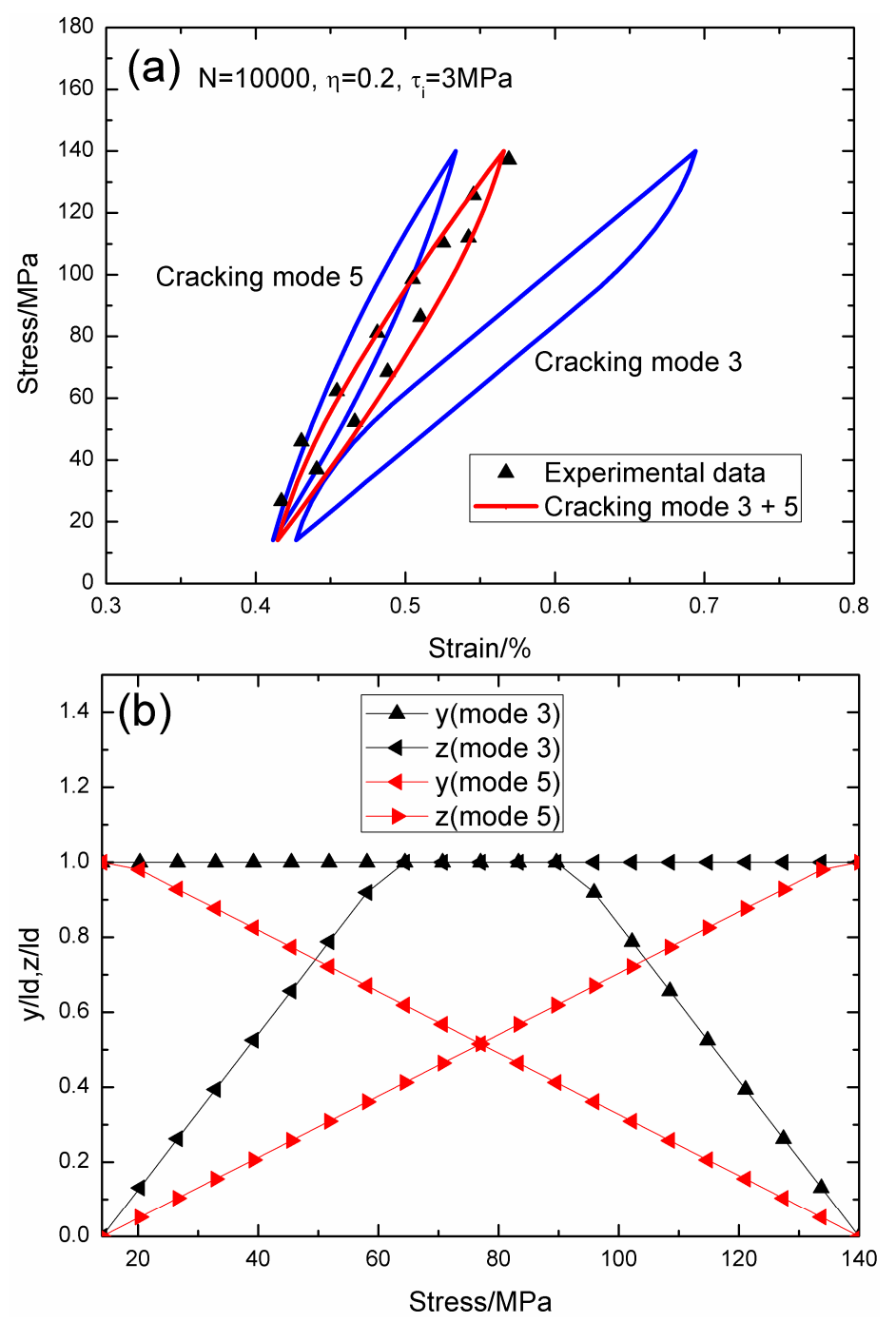

Figure 13. (a) The theoretical and experimental hysteresis loops; and (b) the interface slip lengths, i.e., $y / l_{\mathrm{d}}$ and $z / l_{\mathrm{d}}$, of matrix cracking modes 3 and 5 of $2 \mathrm{D}$ woven $\mathrm{SiC} / \mathrm{SiC}$ composite under $\sigma_{\max }=140 \mathrm{MPa}$ at $1200^{\circ} \mathrm{C}$ in steam and a loading frequency of $0.1 \mathrm{~Hz}$ when $N=10,000$.

When $\sigma_{\max }=140 \mathrm{MPa}$ and $f=1 \mathrm{~Hz}$, the experimental and theoretical hysteresis loops, and the interface slip of matrix cracking modes 3 and 5 corresponding to cycle number $N=1000$, 10,000 , and 30,000 are illustrated in Figures 14-16. When $N=1000$, the hysteresis loops of matrix cracking modes 3 and 5, and the composite and experimental data are given in Figure 14a, in which the proportion of matrix cracking mode 3 is $\eta=0.2$. For matrix cracking mode 3 , the hysteresis loops correspond to interface slip Case 2, as shown in Figure 14b. Upon unloading to the valley stress, the interface counter-slip length approaches $53.9 \%$ of the interface debonded length, i.e., $y\left(\sigma_{\min }\right) / l_{\mathrm{d}}=53.9 \%$; and upon reloading to the peak stress, the interface new-slip length approaches $53.9 \%$ of the interface debonded length, i.e., $z\left(\sigma_{\max }\right) / l_{\mathrm{d}}=53.9 \%$. For matrix cracking mode 5 , the hysteresis loops correspond to interface slip Case 2, as shown in Figure 14b. Upon unloading to the valley stress, the interface counter-slip length approaches $70.2 \%$ of the interface debonded length, i.e., $y\left(\sigma_{\min }\right) / l_{\mathrm{d}}=70.2 \%$; and upon reloading to the peak stress, the interface new slip length approaches $70.2 \%$ of the interface debonded length, i.e., $z\left(\sigma_{\max }\right) / l_{\mathrm{d}}=70.2 \%$. 

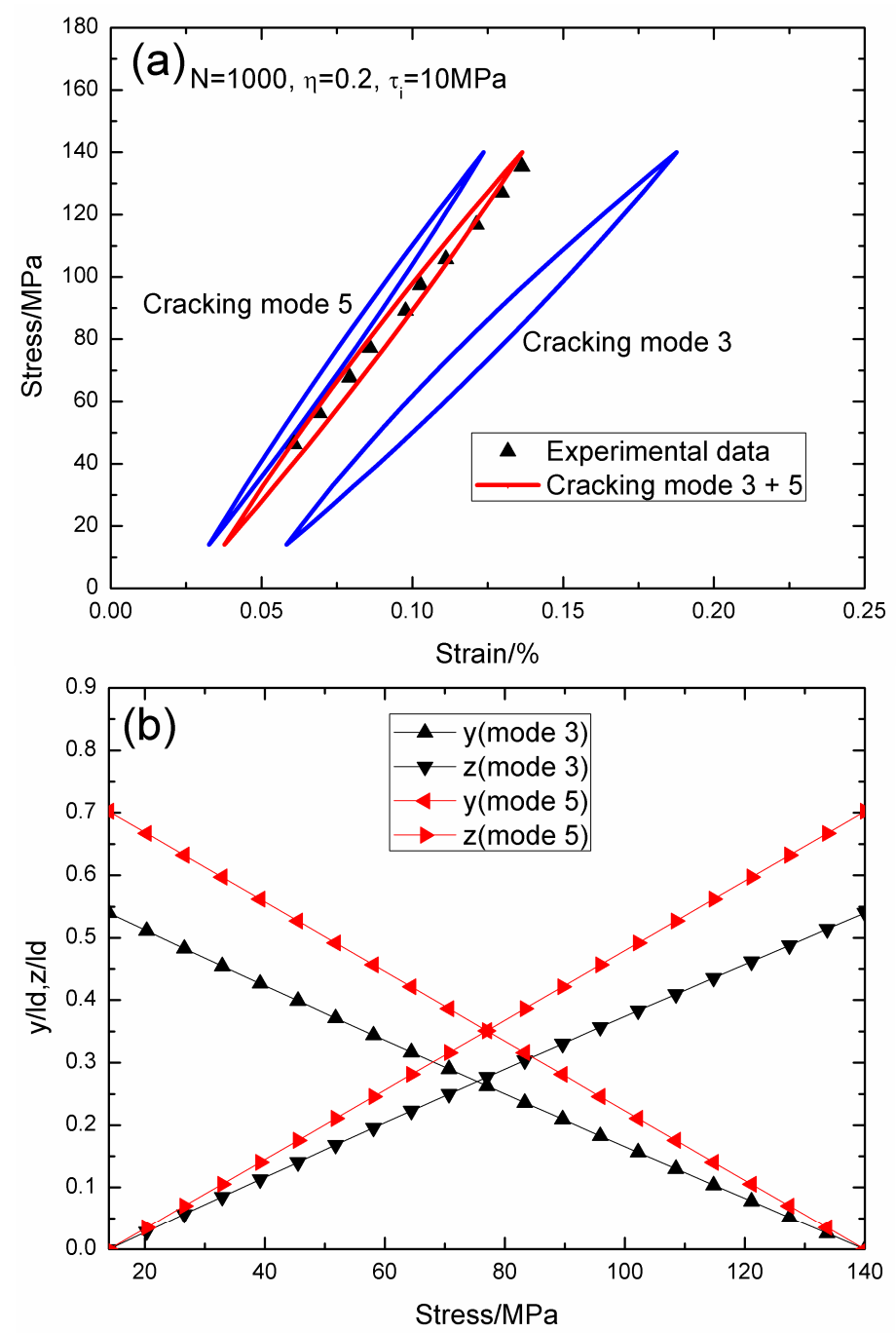

Figure 14. (a) The theoretical and experimental hysteresis loops; and (b) the interface slip lengths, i.e., $y / l_{\mathrm{d}}$ and $z / l_{\mathrm{d}}$, of matrix cracking modes 3 and 5 of $2 \mathrm{D}$ woven $\mathrm{SiC} / \mathrm{SiC}$ composite under $\sigma_{\max }=140 \mathrm{MPa}$ at $1200{ }^{\circ} \mathrm{C}$ in steam and a loading frequency of $1.0 \mathrm{~Hz}$ when $N=1000$.

When $N=10,000$, the hysteresis loops of matrix cracking mode 3 and mode 5 , the composite and experimental data are given in Figure 15a, in which the proportion of matrix cracking mode 3 is $\eta=0.2$. For matrix cracking mode 3 , the hysteresis loops correspond to interface slip Case 4 , as shown in Figure 15b. Upon unloading, the interface counter-slip length approaches the interface debonded length at $\sigma_{\text {tr_fu }}=77 \mathrm{MPa}$, i.e., $y\left(\sigma_{\text {tr_fu }_{-}}\right) / l_{\mathrm{d}}=1$; and upon reloading to $\sigma_{\mathrm{tr} \_ \text {fr }}=77 \mathrm{MPa}$, the interface new slip length approaches the interface debonded length, i.e., $z\left(\sigma_{\mathrm{tr} \_\mathrm{fr}}\right) / l_{\mathrm{d}}=1$. For matrix cracking mode 5 , the hysteresis loops correspond to interface slip Case 2, as shown in Figure 15b. Upon unloading to the valley stress, the interface counter-slip length approaches $69.3 \%$ of the interface debonded length, i.e., $y\left(\sigma_{\min }\right) / l_{\mathrm{d}}=69.3 \%$; and upon reloading to the peak stress, the interface new slip length approaches $69.3 \%$ of the interface debonded length, i.e., $z\left(\sigma_{\max }\right) / l_{\mathrm{d}}=69.3 \%$. 

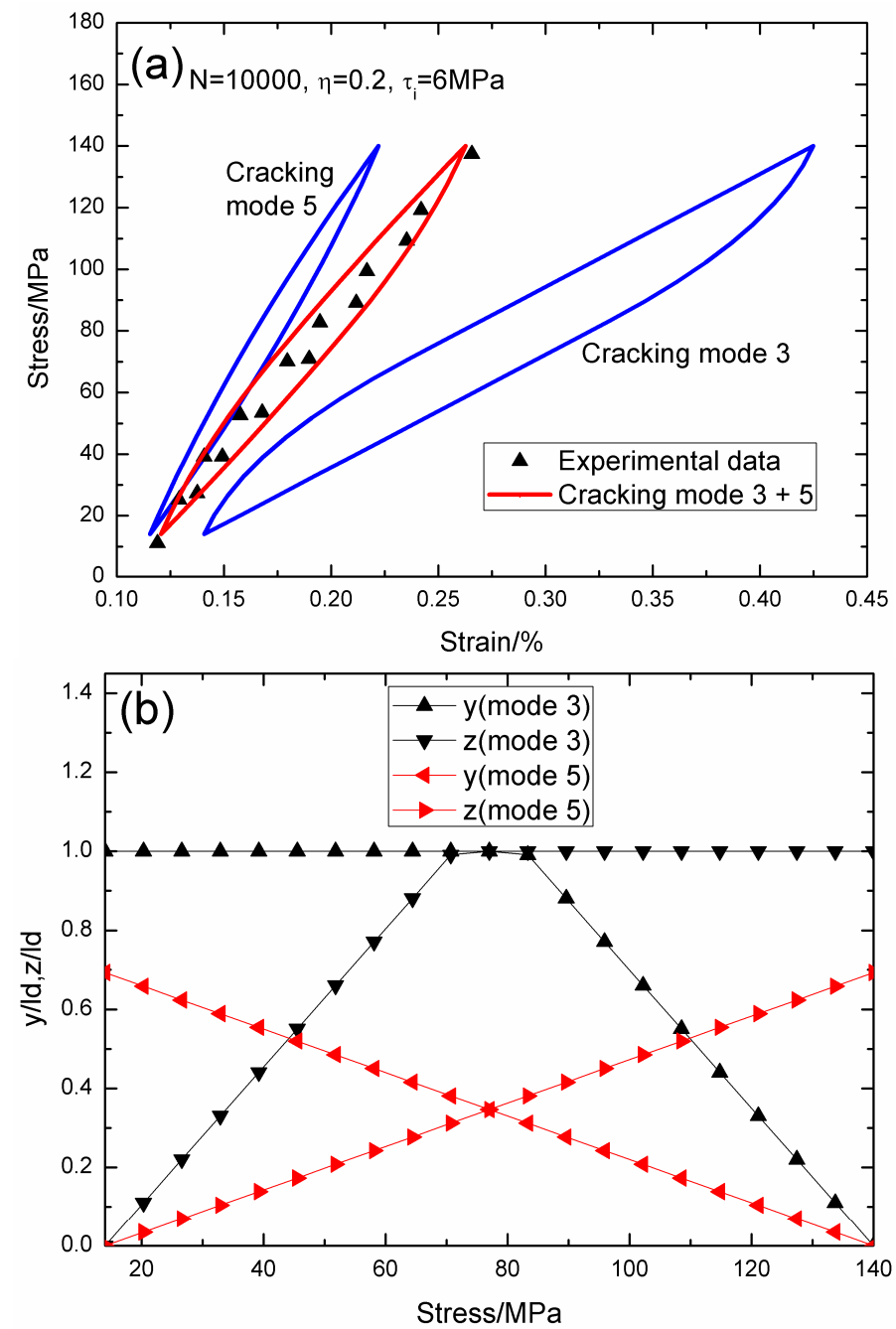

Figure 15. (a) The theoretical and experimental hysteresis loops; and (b) the interface slip lengths, i.e., $y / l_{\mathrm{d}}$ and $z / l_{\mathrm{d}}$, of matrix cracking modes 3 and 5 of $2 \mathrm{D}$ woven $\mathrm{SiC} / \mathrm{SiC}$ composite under $\sigma_{\max }=140 \mathrm{MPa}$ at $1200^{\circ} \mathrm{C}$ in steam and a loading frequency of $1.0 \mathrm{~Hz}$ when $N=10,000$.

When $N=30,000$, the hysteresis loops of matrix cracking modes 3 and 5, and the composite and experimental data are given in Figure 16a, in which the proportion of matrix cracking mode 3 is $\eta=0.2$. For matrix cracking mode 3 , the hysteresis loops correspond to interface slip Case 4 , as shown in Figure 16b. Upon unloading, the interface counter-slip length approaches the interface debonded length at $\sigma_{\text {tr_fu }_{-}}=108.5 \mathrm{MPa}$, i.e., $y\left(\sigma_{\text {tr_fu }_{-}}\right) / l_{\mathrm{d}}=1$; and upon reloading to $\sigma_{\text {tr_fr }_{-}}=45.5 \mathrm{MPa}$, the interface new slip length approaches the interface debonded length, i.e., $z\left(\sigma_{\mathrm{tr}_{f} \mathrm{fr}}\right) / l_{\mathrm{d}}=1$. For matrix cracking mode 5, the hysteresis loops correspond to interface slip Case 4, as shown in Figure 16b. Upon unloading, the interface counter-slip length approaches the interface debonded length at $\sigma_{\text {tr_fu }}=14 \mathrm{MPa}$, i.e., $y\left(\sigma_{\text {tr_fu }}\right) / l_{\mathrm{d}}=1$; and upon reloading to $\sigma_{\text {tr_fr }}=140 \mathrm{MPa}$, the interface new slip length approaches the interface debonded length, i.e., $z\left(\sigma_{\text {tr_fr }}\right) / l_{\mathrm{d}}=1$. 

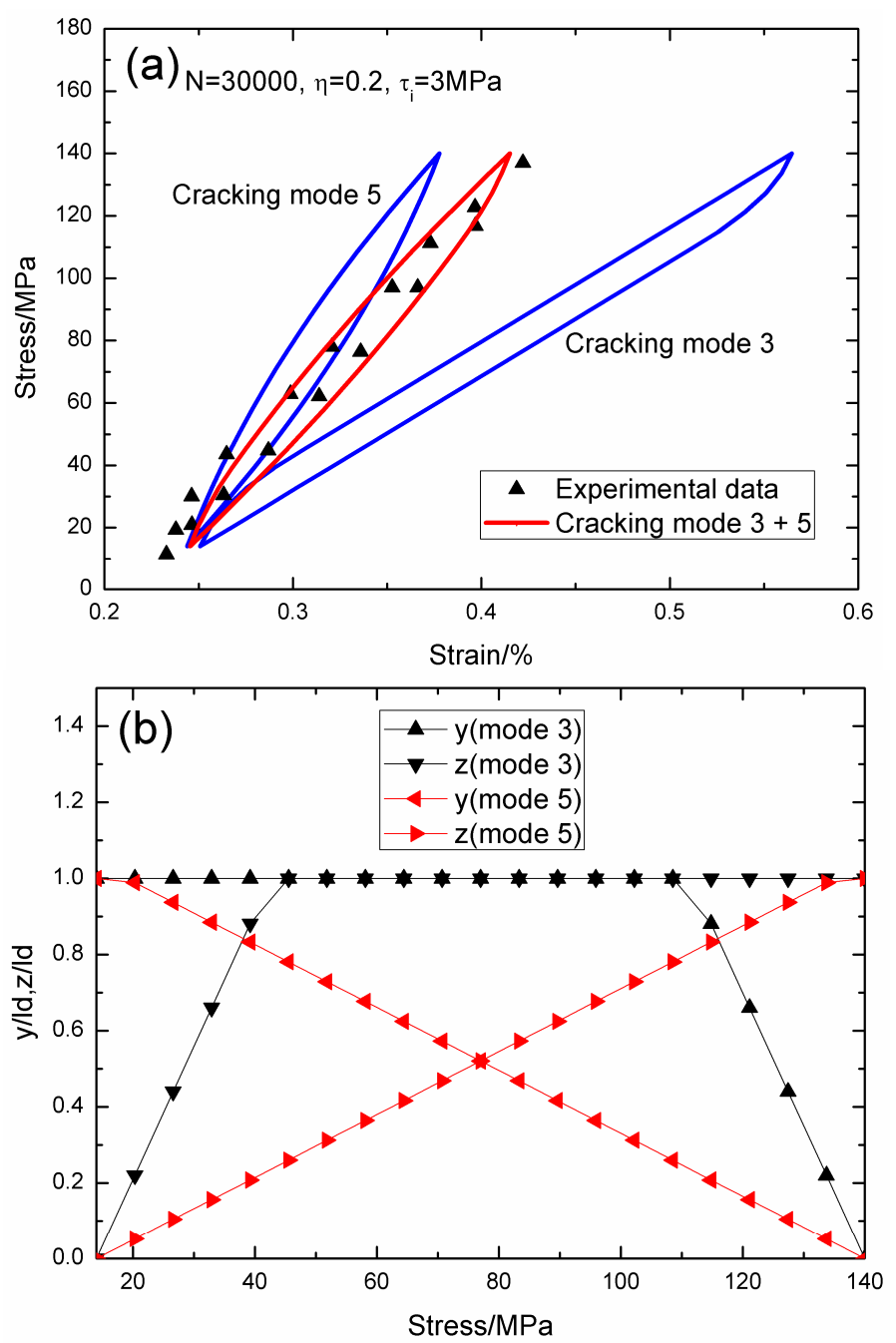

Figure 16. (a) The theoretical and experimental hysteresis loops; and (b) the interface slip lengths, i.e., $y / l_{\mathrm{d}}$ and $z / l_{\mathrm{d}}$, of matrix cracking modes 3 mode 5 of $2 \mathrm{D}$ woven $\mathrm{SiC} / \mathrm{SiC}$ composite under $\sigma_{\max }=140 \mathrm{MPa}$ at $1200{ }^{\circ} \mathrm{C}$ in steam and a loading frequency of $1.0 \mathrm{~Hz}$ when $N=30,000$.

\subsection{Discussion}

Under cyclic fatigue loading, matrix multicracking occurs upon first loading to the maximum stress, and approaches saturation upon initial cycles. During and after saturation has occurred, the matrix cracks become excellent channels for crack propagation and, hence, environmental attack. Once open to the effects of oxygen, the $\mathrm{SiC}$ matrix and fibers tend to either volatize or oxidize through the formation of $\mathrm{SiO}_{2}$. The presence of steam within the environment significantly increases the degradation of CMCs, i.e., the increase of interphase oxidation, and interface shear stress degradation, which would affect the shape, location, and area of hysteresis loops. The interface shear stress degradation rate $\psi$ is defined by Equation (16):

$$
\psi=\frac{\tau_{\text {initial }}-\tau_{\text {final }}}{N_{\text {initial }}-N_{\text {final }}}
$$

where $\tau_{\text {initial }}$ and $\tau_{\text {final }}$ denote the interface shear stress at cycle numbers $N_{\text {initial }}$ and $N_{\text {final }} ;$ and $N_{\text {initial }}$ and $N_{\text {final }}$ denote the initial and final cycle number.

Under fatigue peak stress of $\sigma_{\max }=60 \mathrm{MPa}$ at $1000{ }^{\circ} \mathrm{C}$ in steam, the proportion of matrix cracking mode 3 occupies $20 \%$ of all matrix cracking modes in the $2 \mathrm{D} \mathrm{SiC} / \mathrm{SiC}$ composite; and the interface shear stress decreases from $15 \mathrm{MPa}$ at the 2 nd cycle to $3 \mathrm{MPa}$ at the 190,000th cycle, due 
to interphase oxidation in steam conditions; and the hysteresis loops of matrix cracking mode 3 and mode 5 correspond to interface slip Case 2 and Case 2 at the 2nd cycle to Case 3 and Case 2 at the 190,000 th cycle. The interface shear stress degradation rate is $6.3 \times 10^{-4} \mathrm{MPa} /$ cycle. Under fatigue peak stress of $\sigma_{\max }=100 \mathrm{MPa}$ at $1000{ }^{\circ} \mathrm{C}$ in steam, the proportion of matrix cracking mode 3 occupies $40 \%$ of all matrix cracking modes in the $2 \mathrm{D} \mathrm{SiC} / \mathrm{SiC}$ composite; and the interface shear stress decreases from $15 \mathrm{MPa}$ at the 2 nd cycle to $8 \mathrm{MPa}$ at the 10,000 th cycle, due to interphase oxidation in steam condition; and the hysteresis loops of matrix cracking mode 3 and mode 5 both correspond to interface slip Case 2 from the 2nd cycle to 10,000th cycle. The interface shear stress degradation rate is $7 \times 10^{-4} \mathrm{MPa} /$ cycle. Reynaud [3] investigated the tension-tension fatigue behavior of $2 \mathrm{D}$ woven $\mathrm{SiC} / \mathrm{SiC}$ composite at $1000{ }^{\circ} \mathrm{C}$ in inert. The fatigue peak stress was $\sigma_{\max }=130 \mathrm{MPa}$, and the valley stress was $\sigma_{\min }=$ zero MPa. The loading frequency was $1 \mathrm{~Hz}$. By comparing the experimental fatigue hysteresis dissipated energy with theoretical computational values, Li and Song [28] estimated the interface shear stress of the $2 \mathrm{D} \mathrm{SiC} / \mathrm{SiC}$ composite at $1000{ }^{\circ} \mathrm{C}$ in inert conditions, corresponding to different cycle numbers. It was found that interface shear stress decreases from $19 \mathrm{MPa}$ at the 22th cycle to $8.5 \mathrm{MPa}$ at the 117,055 th cycle. The interface shear stress degradation rate is $8.9 \times 10^{-5} \mathrm{MPa} / \mathrm{cycle}$. The interface shear stress degradation rate increases with increasing fatigue peak stress, i.e., from $6.3 \times 10^{-4} \mathrm{MPa} /$ cycle under $\sigma_{\max }=60 \mathrm{MPa}$ to $7 \times 10^{-4} \mathrm{MPa} /$ cycle under $\sigma_{\max }=100 \mathrm{MPa}$, and is higher in steam conditions, i.e., $6.3 \times 10^{-4} \mathrm{MPa} /$ cycle at $1000{ }^{\circ} \mathrm{C}$ in steam under $\sigma_{\max }=60 \mathrm{MPa}$, than that in the inert atmosphere, i.e., $8.9 \times 10^{-5} \mathrm{MPa} /$ cycle at $1000{ }^{\circ} \mathrm{C}$ in inert conditions under $\sigma_{\text {max }}=130 \mathrm{MPa}$.

Under fatigue peak stress of $\sigma_{\max }=140 \mathrm{MPa}$ at $1200^{\circ} \mathrm{C}$ in steam, the proportion of matrix cracking mode 3 occupies $20 \%$ of all matrix cracking modes in 2D woven $\mathrm{SiC} / \mathrm{SiC}$ composite. When the loading frequency is $0.1 \mathrm{~Hz}$, the interface shear stress decreases from $12 \mathrm{MPa}$ at the 100th cycle to $3 \mathrm{MPa}$ at the 10,000th cycle, due to interphase oxidation in steam conditions; and the hysteresis loops of matrix cracking modes 3 and 5 correspond to interface slip Case 2 and Case 2 when $N=100$, Case 4 and Case 2 when $N=1000$, and Case 4 and Case 4 when $N=10,000$, respectively. The interface shear stress degradation rate is $9 \times 10^{-4} \mathrm{MPa}$ /cycle. When the loading frequency is $1 \mathrm{~Hz}$, the interface shear stress decreases from $10 \mathrm{MPa}$ at the 1000th cycle to $3 \mathrm{MPa}$ at the 30,000th cycle, due to interphase oxidation in steam conditions; and the hysteresis loops of matrix cracking mode 3 and mode 5 correspond to interface slip Case 2 and Case 2 when $N=1000$, Case 2 and Case 4 when $N=10,000$, and Case 4 and Case 4 when $N=30,000$, respectively. The interface shear stress degradation rate is $2 \times 10^{-4} \mathrm{MPa} / \mathrm{cycle}$. The interface shear stress degradation rate under low loading frequency is higher than that under high loading frequency, i.e., $9 \times 10^{-4} \mathrm{MPa} /$ cycle at loading frequency of $0.1 \mathrm{~Hz}$, versus $2 \times 10^{-4} \mathrm{MPa} /$ cycle at loading frequency of $1 \mathrm{~Hz}$.

\section{Conclusions}

The cyclic fatigue hysteresis loops of $2 \mathrm{D}$ woven $\mathrm{SiC} / \mathrm{SiC}$ composite at elevated temperatures in steam have been investigated. The interface slip between fibers and the matrix existing in matrix cracking modes 3 and 5 is considered to be the major reason for the hysteresis loops of $2 \mathrm{D}$ woven CMCs. The hysteresis loops of $2 \mathrm{D} \mathrm{SiC} / \mathrm{SiC}$ composite corresponding to different peak stresses, test conditions, and loading frequencies have been predicted in the present analysis.

1. The damage parameter, i.e., the proportion of matrix cracking mode 3 in the entire matrix cracking modes of the composite, and the hysteresis dissipated energy increase with increasing fatigue peak stress.

2. With increasing cycle number, the interface shear stress in the longitudinal yarns decreases, leading to the transition of interface slip type of matrix cracking modes 3 and 5; the interface shear stress degradation rate increases with increasing fatigue peak stress and decreasing loading frequency, and is higher in steam conditions than in the inert atmosphere. 
Acknowledgments: The author thanks the Science and Technology Department of Jiangsu Province for the funding that made this research possible. The author also wishes to thank the two anonymous reviewers and editors for their helpful comments on an earlier version of the paper; This study received support from the Science and Technology Department of Jiangsu Province through the Natural Science Foundation of Jiangsu Province (Grant No. BK20140813), and the Fundamental Research Funds for the Central Universities (Grant No. NS2016070).

Conflicts of Interest: The author declares no conflict of interest.

\section{References}

1. Naslain, R. Design, preparation and properties of non-oxide CMCs for application in engines and nuclear reactors: An overview. Compos. Sci. Technol. 2004, 64, 155-170. [CrossRef]

2. Bednarcyk, B.A.; Mital, S.K.; Pineda, E.J.; Arnold, S.M. Multiscale modeling of ceramic matrix composites. In Proceedings of the 56th AIAA/ASCE/AHS/ASC Structures, Structural Dynamics, and Materials Conference, Kissimmee, FL, USA, 5-9 January 2015.

3. Reynaud, P. Cyclic fatigue of ceramic-matrix composites at ambient and elevated temperatures. Compos. Sci. Technol. 1996, 56, 809-814. [CrossRef]

4. Fantozzi, G.; Reynaud, P. Mechanical hysteresis in ceramic matrix composites. Mater. Sci. Eng. Part A 2009, 521-522, 18-23. [CrossRef]

5. Kotil, T.; Holmes, J.W.; Comninou, M. Origin of hysteresis observed during fatigue of ceramic matrix composites. J. Am. Ceram. Soc. 1990, 73, 1879-1883. [CrossRef]

6. Pryce, A.W.; Smith, P.A. Matrix cracking in unidirectional ceramic matrix composites under quasi-static and cyclic loading. Acta Metall. Mater. 1993, 41, 1269-1281. [CrossRef]

7. Ahn, B.K.; Curtin, W.A. Strain and hysteresis by stochastic matrix cracking in ceramic matrix composites. J. Mech. Phys. Solids 1997, 45, 177-209. [CrossRef]

8. Solti, J.P.; Mall, S.; Robertson, D.D. Modeling damage in unidirectional ceramic-matrix composites. Compos. Sci. Technol. 1995, 54, 55-66. [CrossRef]

9. Vagaggini, E.; Domergue, J.M.; Evans, A.G. Relationships between hysteresis measurements and the constituent properties of ceramic matrix composites: I, theory. J. Am. Ceram. Soc. 1995, 78, 2709-2720. [CrossRef]

10. Hutchison, J.W.; Jensen, H.M. Models of fiber debonding and pullout in brittle composites with friction. Mech. Mater. 1990, 9, 139-163. [CrossRef]

11. Cho, C.D.; Holmes, J.W.; Barber, J.R. Estimation of interfacial shear in ceramic composites from frictional heating measurements. J. Am. Ceram. Soc. 1991, 74, 2802-2808. [CrossRef]

12. Li, L.B.; Song, Y.D.; Sun, Z.G. Influence of interface de-bonding on the fatigue hysteresis loops of ceramic matrix composites. J. Solid. Mech. 2009, 30, 8-14. (In Chinese)

13. Li, L.B.; Song, Y.D.; Sun, Z.G. Effect of fiber Poisson contraction on fatigue hysteresis loops of ceramic matrix composites. J. Nanjing Univ. Aeronaut. Astronaut. 2009, 41, 181-186.

14. Li, L.B.; Song, Y.D. Influnece of fiber failure on fatigue hysteresis loops of ceramic matrix composites. J. Reinf. Plast. Compos. 2011, 30, 12-25.

15. Li, L.B. Modeling the effect of interface wear on fatigue hysteresis behavior of carbon fiber-reinforced ceramic-matrix composites. Appl. Compos. Mater. 2015, 22, 887-920.

16. Li, L.B.; Song, Y.D.; Sun, Y.C. Estimate interface shear stress of unidirectional C/SiC ceramic matrix composites from hysteresis loops. Appl. Compos. Mater. 2013, 20, 693-707. [CrossRef]

17. Evans, A.G.; Domergue, J.M.; Vagaggini, E. Methodology for relating the tensile constitutive behavior of ceramic-matrix composites to constituent properties. J. Am. Ceram. Soc. 1994, 77, 1425-1435. [CrossRef]

18. Steen, M. Tensile mastercurve of ceramic matrix composites: Significance and implications for modelling. Mater. Sci. Eng. A 1998, 250, 241-248. [CrossRef]

19. Camus, G.; Guillaumat, L.; Baste, S. Development of damage in a 2D woven C/SiC composite under mechanical loading: I. Mechanical characterization. Compos. Sci. Technol. 1996, 56, 1363-1372. [CrossRef]

20. Mei, H. Measurement and calculation of thermal residual stress in fiber reinforced ceramic matrix composites. Compos. Sci. Technol. 2008, 68, 3285-3292. [CrossRef]

21. Mei, H.; Cheng, L.F. Comparison of the mechanical hysteresis of carbon/ceramic-matrix composites with different fiber preforms. Carbon 2009, 47, 1034-1042. [CrossRef] 
22. Dassios, K.G.; Aggelis, D.G.; Kordatos, E.Z.; Matikas, T.E. Cyclic loading of a SiC-fiber reinforced ceramic matrix composite reveals damage mechanisms and thermal residual stress state. Compos. Part A Appl. Sci. Manuf. 2013, 44, 105-113. [CrossRef]

23. Dassios, K.G.; Matikas, T.E. Residual stress-related common intersection points in the mechanical behavior of ceramic matrix composites undergoing cyclic loading. Exp. Mech. 2013, 53, 1033-1038. [CrossRef]

24. Kuo, W.S.; Chou, T.W. Multiple cracking of unidirectional and cross-plyceramic matrix composites. J. Am. Ceram. Soc. 1995, 78, 745-755. [CrossRef]

25. Lamon, J. A micromechanics-based approach to the mechanical behavior of brittle-matrix composites. Compos. Sci. Technol. 2001, 61, 2259-2272. [CrossRef]

26. Michael, K. Fatigue Behavior of a SiC/SiC Composite at $1000{ }^{\circ} \mathrm{C}$ in Air and Steam. Master's Thesis, Air Force Institute of Technology, Wright-Patterson Air Force Base, Greene and Montgomery Counties, $\mathrm{OH}$, USA, December 2010.

27. Jacob, D. Fatigue Behavior of an Advanced SiC/SiC Composite with an Oxidation Inhibited Matrix at $1200^{\circ} \mathrm{C}$ in Air and in Steam. Master's Thesis, Air Force Institute of Technology, Wright-Patterson Air Force Base, Greene and Montgomery Counties, OH, USA, March 2010.

28. Li, L.B.; Song, Y.D. Estimate interface shear stress of woven ceramic matrix composites from hysteresis loops. Appl. Compos. Mater. 2013, 20, 993-1005. [CrossRef]

(c) 2016 by the author; licensee MDPI, Basel, Switzerland. This article is an open access article distributed under the terms and conditions of the Creative Commons Attribution (CC-BY) license (http:/ / creativecommons.org/licenses/by/4.0/). 